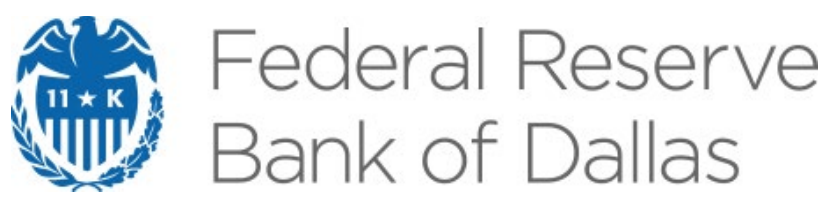

\title{
Online Appendix - Get the Lowdown: Building a Structural Open-Economy Model of the U.S. Natural Rate of Interest
}

Enrique Martínez-García

Globalization Institute Working Paper 403 Appendix October 2020

Research Department https://doi.org/10.24149/gwp403app

Working papers from the Federal Reserve Bank of Dallas are preliminary drafts circulated for professional comment. The views in this paper are those of the authors and do not necessarily reflect the views of the Federal Reserve Bank of Dallas or the Federal Reserve System. Any errors or omissions are the responsibility of the authors. 


\title{
Online Appendix - Get the Lowdown: Building a Structural Open-Economy Model of the U.S. Natural Rate of Interest ${ }^{*}$
}

\author{
Enrique Martínez-García ${ }^{\dagger}$
}

October 5, 2020

\begin{abstract}
This note describes the building blocks of the workhorse two-country dynamic stochastic general equilibrium (DSGE) model with complete asset markets and nominal rigidities subject to country-specific productivity, cost-push, and monetary policy shocks. The note also discusses the significance of the occasionally-binding zero-lower bound constraint on the policy rate for estimating the model. Finally, the note also proposes a simple method with which to obtain structural estimates that are consistent with the zero-lower bound augmenting the main (log-linearized) equilibrium conditions of the model with a set of auxiliary measurement equations that constrain the endogenous expectations to align with observed survey-based expectations. This is because those survey-based expectations are formed by private agents that are aware of and have internalized the effects of the zero-lower bound on the future path of the economy.
\end{abstract}

JEL Classification: C11, C13, E43, E58, F41.

Keywords: Open-Economy Model, New Keynesian Workhorse, Monetary Policy, ZeroLower Bound Constraint, Bayesian Estimation.

\footnotetext{
* This document provides supplementary materials and derivations for the paper "Get the Lowdown: The International Side of the Fall in the U.S. Natural Rate of Interest" (in Martínez-García (2020b)). This work has greatly benefited from valuable feedback provided by James Bullard, Michael B. Devereux, Charles Engel, Marc P. Giannoni, Joseph H. Haslag, Ivan Jeliazkov, John Keating, Fabio Milani, Dale J. Poirier, Giorgio Primiceri, Eric Sims, Eric Swanson, John B. Taylor, Víctor Valcárcel, and the many participants at the 2018 Advances in Econometrics conference in UC-Irvine and at the 4th International Workshop on Financial Markets and Nonlinear Dynamics held in Paris in 2019. I acknowledge the excellent research assistance provided by Valerie Grossman, Jarod Coulter, and Abigail Boatwright. The codes and data needed to replicate the results of this paper can be found here: https://bit.ly/2MgmRWJ. All remaining errors are mine alone. The views expressed here do not necessarily reflect those of the Federal Reserve Bank of Dallas or the Federal Reserve System.

${ }^{\dagger}$ Enrique Martínez-García, Federal Reserve Bank of Dallas, 2200 N. Pearl Street, Dallas, TX 75201. Phone: (214) 9225262. Fax: (214) 922-5194. E-mail: emg.economics@gmail.com. Webpage: https://sites.google.com/view/emgeconomics.
} 


\section{The Workhorse New Keynesian Model}

The model is a variant of the workhorse two-country New Keynesian model developed and studied in Martínez-García and Wynne (2010), Martínez-García et al. (2012), MartínezGarcía and Wynne (2014), Martínez-García (2015), and Martínez-García (2019). Here I describe the main features of that framework maintaining the assumption that the structure of both countries is symmetric and that there is an equal mass of identical households and varieties of goods in each country spanning the unit interval. Accordingly, I illustrate the two-country model with the first principles from the Home country unless otherwise noted and use the superscript $*$ to denote Foreign country variables. These derivations complement the empirical exploration of this framework conducted in Martínez-García (2020b).

\subsection{Households' Labor Supply and Consumption Behavior}

The lifetime utility of the representative household in the Home country is additively separable in consumption, $C_{t}$, and labor, $L_{t}$, i.e.,

$$
\sum_{\tau=0}^{+\infty} \beta^{\tau} \mathbb{E}_{t}\left[\frac{1}{1-\gamma}\left(C_{t+\tau}\right)^{1-\gamma}-\frac{\chi}{1+\varphi}\left(L_{t+\tau}\right)^{1+\varphi}\right]
$$

where $0<\beta<1$ is the subjective intertemporal discount factor, $\gamma>0$ is the inverse of the intertemporal elasticity of substitution, and $\varphi>0$ is the inverse of the Frisch elasticity of labor supply. The scaling factor $\chi>0$ pins down labor in steady state. The household maximizes its lifetime utility in (1) subject to the following sequence of budget constraints which holds for all states of nature $\omega_{t} \in \Omega$, i.e.,

$$
\begin{gathered}
P_{t} C_{t}+\int_{\omega_{t+1} \in \Omega} Q_{t}\left(\omega_{t+1}\right) B_{t}^{H}\left(\omega_{t+1}\right)+S_{t} \int_{\omega_{t+1} \in \Omega} Q_{t}^{*}\left(\omega_{t+1}\right) B_{t}^{F}\left(\omega_{t+1}\right) \\
\leq B_{t-1}^{H}\left(\omega_{t}\right)+S_{t} B_{t-1}^{F}\left(\omega_{t}\right)+W_{t} L_{t}+P r_{t}-T_{t}
\end{gathered}
$$

where $W_{t}$ is the nominal wage in the Home country, $P_{t}$ is the Home consumer price index (CPI), $T_{t}$ is a nominal lump-sum tax (or transfer) imposed by the Home government, and $\mathrm{Pr}_{t}$ are (per-period) nominal profits from all firms producing the Home varieties. $S_{t}$ refers to the bilateral nominal exchange rate, i.e., the units of the currency of the Home country that can be obtained per unit of the Foreign country currency at time $t$.

Home firms produce their variety of output subject to a linear-in-labor technology, i.e., $Y_{t}(h)=A_{t} L_{t}(h)$ for each variety $h \in[0,1]$. Producing each variety $h$, therefore, depends 
on an exogenous aggregate Home productivity shock, $A_{t}$, and household labor, $L_{t}(h)$, such that

$$
L_{t}=\int_{0}^{1} L_{t}(h) d h .
$$

This market clearing condition simply states that the labor employed by all firms must be equal to the labor supply offered by the representative household. I assume full withincountry labor mobility ensuring that wages equalize across all local firms. However, labor remains immobile across countries and wages do not necessarily equate across countries. From the household's first-order conditions, I obtain a labor supply equation of the following form,

$$
\frac{W_{t}}{P_{t}}=\chi\left(C_{t}\right)^{\gamma}\left(L_{t}\right)^{\varphi}
$$

which equates the real wage $\frac{W_{t}}{P_{t}}$ to the marginal utility of labor over the marginal utility of consumption.

The household's budget constraint includes a portfolio of one-period Arrow-Debreu securities (contingent bonds) internationally traded, issued in the currencies of both countries, and in zero net-supply. Specifically, the pair $\left\{B_{t}^{H}\left(\omega_{t+1}\right), B_{t}^{F}\left(\omega_{t+1}\right)\right\}$ refers to the portfolio of contingent bonds issued by both countries and held equally by each household of the Home country. Access to a full set of internationally-traded, one-period Arrow-Debreu securities has the implication that it completes the local and international asset markets recursively. The prices of the Home and Foreign contingent bonds expressed in their currencies of denomination are denoted $Q_{t}\left(\omega_{t+1}\right)$ and $Q_{t}^{*}\left(\omega_{t+1}\right)$, respectively. ${ }^{1}$

Under complete asset markets, standard no-arbitrage results imply that $Q_{t}\left(\omega_{t+1}\right)=$ $\frac{S_{t}}{S_{t+1}\left(\omega_{t+1}\right)} Q_{t}^{*}\left(\omega_{t+1}\right)$ for every state of nature $\omega_{t} \in \Omega$. Hence, Home and Foreign households can efficiently share risks domestically as well as internationally. This implies that the intertemporal marginal rate of substitution is equalized across countries at each possible state of nature and, accordingly, it follows that:

$$
\beta\left(\frac{C_{t}}{C_{t-1}}\right)^{-\gamma} \frac{P_{t-1}}{P_{t}}=\beta\left(\frac{C_{t}^{*}}{C_{t-1}^{*}}\right)^{-\gamma} \frac{P_{t-1}^{*} S_{t-1}}{P_{t}^{*} S_{t}} .
$$

I define the bilateral real exchange rate as $R S_{t} \equiv \frac{S_{t} P_{t}^{*}}{P_{t}}$, so by backward recursion the perfect

\footnotetext{
${ }^{1}$ The price of each bond in the currency of the country who did not issue the bond is converted at the prevailing bilateral exchange rate with full exchange rate pass-through under the law of one price (LOOP).
} 
international risk-sharing condition in (5) implies that:

$$
R S_{t}=v\left(\frac{C_{t}^{*}}{C_{t}}\right)^{-\gamma}
$$

where $v \equiv \frac{S_{0} P_{0}^{*}}{P_{0}}\left(\frac{C_{0}^{*}}{C_{0}}\right)^{\gamma}$ is a constant that depends on initial conditions. If the initial conditions correspond to those of the zero-inflation deterministic steady state, then the constant $v$ is simply equal to one.

Yields on redundant one-period, uncontingent nominal bonds in the Home country are derived from the price of the contingent Arrow-Debreu securities. That results in the following standard stochastic Euler equation for the Home country:

$$
\frac{1}{1+i_{t}}=\beta \mathbb{E}_{t}\left[\left(\frac{C_{t+1}}{C_{t}}\right)^{-\gamma} \frac{P_{t}}{P_{t+1}}\right]
$$

where $i_{t}$ is the riskless Home nominal interest rate. Apart from the first-order conditions, the solution to the households' optimization problem is also characterized by the budget constraint of the Home country household given by (2) and the corresponding initial conditions (assumed to be identical for all households). An analogous labor supply equation, Euler equation, and household budget constraint (with the corresponding initial conditions) can be derived for the Foreign country.

Aggregate consumption bundles. $C_{t}$ is the CES aggregator of both countries' bundles of goods for the Home country household and is defined as:

$$
C_{t}=\left[(1-\xi)^{\frac{1}{\sigma}}\left(C_{t}^{H}\right)^{\frac{\sigma-1}{\sigma}}+(\xi)^{\frac{1}{\sigma}}\left(C_{t}^{F}\right)^{\frac{\sigma-1}{\sigma}}\right]^{\frac{\sigma}{\sigma-1}}
$$

where $\sigma>0$ is the elasticity of substitution between the consumption bundle of locallyproduced goods, $C_{t}^{H}$, and the consumption bundle of the foreign-produced goods, $C_{t}^{F}$. The share of imported goods in the consumption basket of the Home country satisfies that $0<$ $\xi \leq \frac{1}{2}$, so these preferences allow for local-consumption bias. Similarly, the CES aggregator for the Foreign country is defined as:

$$
C_{t}^{*}=\left[(\xi)^{\frac{1}{\sigma}}\left(C_{t}^{H *}\right)^{\frac{\sigma-1}{\sigma}}+(1-\xi)^{\frac{1}{\sigma}}\left(C_{t}^{F *}\right)^{\frac{\sigma-1}{\sigma}}\right]^{\frac{\sigma}{\sigma-1}}
$$


where $C_{t}^{F *}$ and $C_{t}^{H *}$ are respectively the consumption bundle of foreign-produced goods and of home-produced goods for the Foreign country household. Analogous to (8), $\sigma>0$ is the elasticity of substitution between Home-produced and Foreign-produced goods and the parameter $\xi$ is the share of imported goods in the Foreign consumption basket. The consumption sub-indexes aggregate consumption over the bundle of differentiated varieties produced by each country and are defined as follows:

$$
\begin{aligned}
C_{t}^{H} & =\left[\int_{0}^{1} C_{t}(h)^{\frac{\theta_{t}-1}{\theta_{t}}} d h\right]^{\frac{\theta_{t}}{\theta_{t}-1}}, C_{t}^{F}=\left[\int_{0}^{1} C_{t}(f)^{\frac{\theta_{t}-1}{\theta_{t}}} d f\right]^{\frac{\theta_{t}}{\theta_{t}-1}}, \\
C_{t}^{H *} & =\left[\int_{0}^{1} C_{t}^{*}(h)^{\frac{\theta_{t}-1}{\theta_{t}}} d h\right]^{\frac{\theta_{t}}{\theta_{t}-1}}, C_{t}^{F *}=\left[\int_{0}^{1} C_{t}^{*}(f)^{\frac{\theta_{t}-1}{\theta_{t}}} d f\right]^{\frac{\theta_{t}}{\theta_{t}-1}},
\end{aligned}
$$

where $\theta_{t}>1$ is the (time-varying) elasticity of substitution across the differentiated varieties within a country.

The CPIs that correspond to this specification of preferences over consumption bundles are:

$$
P_{t}=\left[(1-\xi)\left(P_{t}^{H}\right)^{1-\sigma}+\xi\left(P_{t}^{F}\right)^{1-\sigma}\right]^{\frac{1}{1-\sigma}}, P_{t}^{*}=\left[\xi\left(P_{t}^{H *}\right)^{1-\sigma}+(1-\xi)\left(P_{t}^{F *}\right)^{1-\sigma}\right]^{\frac{1}{1-\sigma}}
$$

and,

$$
\begin{aligned}
P_{t}^{H} & =\left[\int_{0}^{1} P_{t}(h)^{1-\theta_{t}} d h\right]^{\frac{1}{1-\theta_{t}}}, P_{t}^{F}=\left[\int_{0}^{1} P_{t}(f)^{1-\theta_{t}} d f\right]^{\frac{1}{1-\theta_{t}}}, \\
P_{t}^{H *} & =\left[\int_{0}^{1} P_{t}^{*}(h)^{1-\theta_{t}} d h\right]^{\frac{1}{1-\theta_{t}}}, P_{t}^{F *}=\left[\int_{0}^{1} P_{t}^{*}(f)^{1-\theta_{t}} d f\right]^{\frac{1}{1-\theta_{t}}},
\end{aligned}
$$

where $P_{t}^{H}$ and $P_{t}^{F *}$ are the price sub-indexes corresponding to the bundle of varieties produced locally in the Home and Foreign countries, respectively. The price sub-index $P_{t}^{F}$ represents the Home country price of the bundle of Foreign varieties while $P_{t}^{H *}$ is the Foreign country price for the bundle of Home varieties. The price of the variety $h$ produced in the Home country is expressed as $P_{t}(h)$ and $P_{t}^{*}(h)$ in units of the Home and Foreign currency, respectively. Similarly, the price of the variety $f$ produced in the Foreign country is quoted in the Home and Foreign countries as $P_{t}(f)$ and $P_{t}^{*}(f)$, respectively.

Each household decides how much to allocate to the different varieties of goods produced in each country. Given the structure of preferences indicated earlier, the utility maximization 
problem implies that the household's demand for each variety is given by:

$$
\begin{aligned}
C_{t}(h) & =\left(\frac{P_{t}(h)}{P_{t}^{H}}\right)^{-\theta_{t}} C_{t}^{H}, C_{t}(f)=\left(\frac{P_{t}(f)}{P_{t}^{F}}\right)^{-\theta_{t}} C_{t}^{F}, \\
C_{t}^{*}(h) & =\left(\frac{P_{t}^{*}(h)}{P_{t}^{H *}}\right)^{-\theta_{t}} C_{t}^{H *}, C_{t}^{*}(f)=\left(\frac{P_{t}^{*}(f)}{P_{t}^{F *}}\right)^{-\theta_{t}} C_{t}^{F *},
\end{aligned}
$$

while the demand for the bundle of varieties produced by each country is simply equal to:

$$
\begin{aligned}
C_{t}^{H} & =(1-\xi)\left(\frac{P_{t}^{H}}{P_{t}}\right)^{-\sigma} C_{t}, C_{t}^{F}=\xi\left(\frac{P_{t}^{F}}{P_{t}}\right)^{-\sigma} C_{t} \\
C_{t}^{H *} & =\xi\left(\frac{P_{t}^{H *}}{P_{t}^{*}}\right)^{-\sigma} C_{t}^{*}, C_{t}^{F *}=(1-\xi)\left(\frac{P_{t}^{F *}}{P_{t}^{*}}\right)^{-\sigma} C_{t}^{*}
\end{aligned}
$$

These equations relate the demand for each variety-whether produced domestically or imported - to the aggregate consumption of the country.

\subsection{The Firms' Price-Setting Behavior}

Each firm located in either the Home or Foreign country produces one differentiated variety with which it supplies its local market and exports operating under monopolistic competition. I assume producer currency pricing (PCP), so firms set prices by invoicing all sales in their local currency. ${ }^{2}$ The PCP assumption implies that the law of one price (LOOP) holds at the variety level. That is, for each variety $h$ produced in the Home country, it must hold that $P_{t}(h)=S_{t} P_{t}^{*}(h)$; similarly, for each variety $f$ produced in the Foreign country, it holds that $P_{t}(f)=S_{t} P_{t}^{*}(f)$. Hence, the corresponding price sub-indexes in both countries for the same bundle of varieties must satisfy that $P_{t}^{H}=S_{t} P_{t}^{H *}$ and that $P_{t}^{F}=S_{t} P_{t}^{F *}$.

The bilateral terms of trade $T o T_{t} \equiv \frac{P_{t}^{F}}{S_{t} P_{t}^{H *}}$ defines the Home value of the bundle of goods imported from the Foreign country in Home currency units relative to the Foreign value of the bundle of Home country exports quoted in the currency of the Home country at the prevailing bilateral nominal exchange rate $S_{t}$. Under the LOOP, terms of trade can be expressed as:

$$
\operatorname{ToT}_{t} \equiv \frac{P_{t}^{F}}{S_{t} P_{t}^{H *}}=\frac{P_{t}^{F}}{P_{t}^{H}} .
$$

Even though the LOOP holds at the variety and price sub-index levels, the assumption

\footnotetext{
${ }^{2}$ For more in-depth analysis on the role of international price-setting on PPP and the design of optimal monetary policy, see Engel (2009).
} 
of symmetric local-product bias in aggregate consumption implicit in equations (8) - (9) introduces deviations from purchasing power parity (PPP) at the level of the aggregate consumption basket. In other words, in general it is the case that $P_{t} \neq S_{t} P_{t}^{*}$ and, accordingly, the bilateral real exchange rate between both countries deviates from one, i.e., $R S_{t} \equiv \frac{S_{t} P_{t}^{*}}{P_{t}}=$ $\left[\frac{\xi+(1-\xi)\left(T o T_{t}\right)^{1-\sigma}}{(1-\xi)+\xi\left(T o T_{t}\right)^{1-\sigma}}\right]^{\frac{1}{1-\sigma}} \neq 1$ if $\xi \neq \frac{1}{2}$.

Given the households' preferences in each country, the demand for any variety $h \in[0,1]$ produced in the Home country can be written as:

$$
\begin{aligned}
Y_{t}(h) \equiv & C_{t}(h)+C_{t}^{*}(h)=(1-\xi)\left(\frac{P_{t}(h)}{P_{t}^{H}}\right)^{-\theta_{t}}\left(\frac{P_{t}^{H}}{P_{t}}\right)^{-\sigma} C_{t}+\xi\left(\frac{P_{t}(h)}{P_{t}^{H}}\right)^{-\theta_{t}}\left(\frac{P_{t}^{H *}}{P_{t}^{*}}\right)^{-\sigma} C_{t}^{*} \\
& =\left(\frac{P_{t}(h)}{P_{t}^{H}}\right)^{-\theta_{t}}\left(\frac{P_{t}^{H}}{P_{t}}\right)^{-\sigma}\left[(1-\xi) C_{t}+\xi\left(\frac{1}{R S_{t}}\right)^{-\sigma} C_{t}^{*}\right] .
\end{aligned}
$$

The demand for each variety $f \in[0,1]$ produced by a Foreign firm can be derived similarly. Firms maximize profits subject to a partial adjustment rule à la Calvo (1983) at the variety level, that is, subject to sticky prices. In each period, every firm receives either a signal to maintain their prices with probability $0<\alpha<1$ or a signal to re-optimize them with probability $1-\alpha$. At time $t$, the re-optimizing firm producing variety $h$ in the Home country chooses a price $\widetilde{P}_{t}(h)$ optimally to maximize the expected discounted value of its profits, i.e.,

$$
\sum_{\tau=0}^{+\infty} \mathbb{E}_{t}\left\{(\alpha \beta)^{\tau}\left(\frac{C_{t+\tau}}{C_{t}}\right)^{-\gamma} \frac{P_{t}}{P_{t+\tau}}\left[\widetilde{Y}_{t, t+\tau}(h)\left(\widetilde{P}_{t}(h)-(1-\phi) M C_{t+\tau}\right)\right]\right\}
$$

subject to the constraint that the aggregate demand given in (20) is always satisfied at the set price $\widetilde{P}_{t}(h)$ for as long as that price remains unchanged. $\widetilde{Y}_{t, t+\tau}(h)$ indicates the demand for consumption of the variety $h$ produced in the Home country at time $t+\tau(\tau \geq 0)$ whenever the prevailing prices remained unchanged since time $t$, i.e., whenever $P_{t+s}(h)=\widetilde{P}_{t}(h)$ for all $0 \leq s \leq \tau$. An analogous problem describes the optimal price-setting behavior of the re-optimizing firms in the Foreign country.

The (before-subsidy) nominal marginal cost in the Home country, $M C_{t}$, can be expressed as:

$$
M C_{t} \equiv\left(\frac{W_{t}}{A_{t}}\right)
$$

where $A_{t}$ is the Home productivity shocks. A similar expression holds for the Foreign country's (before-subsidy) nominal marginal cost. Productivity shocks are described with the 
following exogenous, bivariate stochastic process:

$$
\begin{aligned}
A_{t} & =(A)^{1-\delta_{a}}\left(A_{t-1}\right)^{\delta_{a}}\left(A_{t-1}^{*}\right)^{\delta_{a, a^{*}}} e^{\varepsilon_{t}^{a}} \\
A_{t}^{*} & =(A)^{1-\delta_{a}}\left(A_{t-1}\right)^{\delta_{a, a^{*}}}\left(A_{t-1}^{*}\right)^{\delta_{a}} e^{\varepsilon_{t}^{a *}} \\
\left(\begin{array}{c}
\varepsilon_{t}^{a} \\
\varepsilon_{t}^{a *}
\end{array}\right) & \sim N\left(\left(\begin{array}{c}
0 \\
0
\end{array}\right),\left(\begin{array}{cc}
\sigma_{a}^{2} & \rho_{a, a^{*}} \sigma_{a}^{2} \\
\rho_{a, a^{*}} \sigma_{a}^{2} & \sigma_{a}^{2}
\end{array}\right)\right),
\end{aligned}
$$

where $A>0$ is the unconditional mean of the process, $-1<\delta_{a}<1$ and $-1<\delta_{a, a^{*}}<1$ capture the persistence and cross-country spillovers, and $\left(\varepsilon_{t}^{u}, \varepsilon_{t}^{u *}\right)^{T}$ is a vector of Gaussian innovations with a common variance $\sigma_{a}^{2}>0$ and possibly correlated across both countries $-1<\rho_{a, a^{*}}<1 .^{3}$

From $(21)$, it follows that the optimal pricing rule $\widetilde{P}_{t}(h)$ of the re-optimizing firm producing variety $h$ in the Home country at time $t$ is given by:

$$
\widetilde{P}_{t}(h)=(1-\phi) U_{t} \frac{\sum_{\tau=0}^{+\infty}(\alpha \beta)^{\tau} \mathbb{E}_{t}\left[\left(\frac{\left(C_{t+\tau}\right)^{-\gamma}}{P_{t+\tau}}\right) \widetilde{Y}_{t, t+\tau}(h) M C_{t+\tau}\right]}{\sum_{\tau=0}^{+\infty}(\alpha \beta)^{\tau} \mathbb{E}_{t}\left[\left(\frac{\left(C_{t+\tau}\right)^{-\gamma}}{P_{t+\tau}}\right) \widetilde{Y}_{t, t+\tau}(h)\right]},
$$

where $\phi$ is a time-invariant labor subsidy which is proportional to the net nominal marginal cost $M C_{t+\tau}$ and $U_{t} \equiv \frac{\theta_{t}}{\theta_{t}-1}$ is the (time-varying) monopolistic competition price mark-up. An analogous expression can be derived to characterize the optimal pricing rule of the reoptimizing firm $f$ in the Foreign country $\widetilde{P}_{t}(f)$. Under monopolistic competition, the price mark-up acts as a "cost-push" shock (a supply-side shifter) and is treated as a purely exogenous, bivariate stochastic process of the following form:

$$
\begin{aligned}
U_{t} & =(U)^{1-\delta_{u}}\left(U_{t-1}\right)^{\delta_{u}} e^{\varepsilon_{t}^{u}} \\
U_{t}^{*} & =(U)^{1-\delta_{u}}\left(U_{t-1}^{*}\right)^{\delta_{u}} e^{\varepsilon_{t}^{u *}} \\
\left(\begin{array}{c}
\varepsilon_{t}^{u} \\
\varepsilon_{t}^{u *}
\end{array}\right) & \sim N\left(\left(\begin{array}{c}
0 \\
0
\end{array}\right),\left(\begin{array}{cc}
\sigma_{u}^{2} & \rho_{u, u^{*}} \sigma_{u}^{2} \\
\rho_{u, u^{*}} \sigma_{u}^{2} & \sigma_{u}^{2}
\end{array}\right)\right),
\end{aligned}
$$

where $U \equiv \frac{\theta}{\theta-1} \geq 1$ is its unconditional mean, $-1<\delta_{u}<1$ captures the persistence, and $\left(\varepsilon_{t}^{u}, \varepsilon_{t}^{u *}\right)^{T}$ is a vector of Gaussian innovations with a common variance $\sigma_{u}^{2}>0$ and possibly

\footnotetext{
${ }^{3}$ Only the stochastic process for productivity shocks incorporates cross-country spillovers, i.e., $-1<$ $\delta_{a, a^{*}}<1$. The associated stochastic process expressed in log-deviations from the steady state requires to be stationary that all eigenvalues of the matrix on the lagged vector be inside the unit circle. It is straightforward to show that stationarity hence implies that $\left|\delta_{a}+\delta_{a, a^{*}}\right|<1$ and $\left|\delta_{a}-\delta_{a, a^{*}}\right|<1$. This, therefore, constraints the range of values for which $\delta_{a, a^{*}}$ is well-defined for a given $-1<\delta_{a}<1$.
} 
correlated across both countries $-1<\rho_{u, u^{*}}<1$.

Given the inherent symmetry of the Calvo (1983)-type pricing scheme, then it follows that $\widetilde{P}_{t}(h)=\widetilde{P}_{t}$ for all re-optimizing firms in the Home country and $\widetilde{P}_{t}^{*}(f)=\widetilde{P}_{t}^{*}$ for all reoptimizing firms in the Foreign country so the indexes $h$ and $f$ themselves become redundant. Furthermore, the price sub-indexes in both countries corresponding to the bundles of varieties produced locally, $P_{t}^{H}$ and $P_{t}^{F *}$ respectively, evolve according to the following laws of motion:

$$
\begin{aligned}
\left(P_{t}^{H}\right)^{1-\theta_{t}} & =\alpha\left(P_{t-1}^{H}\right)^{1-\theta_{t}}+(1-\alpha)\left(\widetilde{P}_{t}\right)^{1-\theta_{t}} \\
\left(P_{t}^{F *}\right)^{1-\theta_{t}} & =\alpha\left(P_{t-1}^{F *}\right)^{1-\theta_{t}}+(1-\alpha)\left(\widetilde{P}_{t}^{*}\right)^{1-\theta_{t}}
\end{aligned}
$$

These equations link the current-period price sub-index to the previous-period price subindex and to the symmetric pricing decision made by all the firms that re-optimize prices during the current period. The LOOP holds with full pass-through of the nominal exchange rate $S_{t}$ at the price sub-index level and, therefore, the LOOP suffices to relate the dynamics of the price sub-indexes $P_{t}^{H}$ and $P_{t}^{F *}$ in $(30)-(31)$ to the price sub-indexes of the same bundles in their export markets $P_{t}^{H *}$ and $P_{t}^{F}$.

\subsection{Monetary (and Fiscal) Policy}

Monopolistic competition in price-setting and wage-setting introduces a wedge between prices and marginal costs in steady state given by $U \equiv \frac{\theta}{\theta-1}$. This distortion arises from the steady-state monopolistic competition price mark-up $\frac{\theta}{\theta-1}$. Accordingly, the distortion is implicitly a function of the steady-state elasticity of substitution across varieties of goods within a country $\theta>1$. Home and Foreign governments raise lump-sum taxes from local households within their borders in order to subsidize labor employment and eliminate those steady-state price mark-ups. An optimal (time-invariant) labor subsidy $\phi$ which is proportional to the marginal cost and set optimally to be equal to $\phi \equiv \frac{1}{\theta}$ in both countries cancels out in steady state the monopolistic competition price mark-ups that are present in the pricing rule given by equation (26).

Monetary policy in the Home country follows a Wicksellian-type Taylor (1993) monetary policy rule. For the Home country, the monetary policy rule can be expressed as:

$$
\left(\frac{1+i_{t}}{1+\bar{i}}\right)=\left(\frac{1+\bar{r}_{t}}{1+\bar{r}}\right) \mathbb{E}_{t}\left(\frac{\Pi_{t+1}}{\bar{\Pi}}\right)\left[\left(\frac{\Pi_{t}}{\bar{\Pi}}\right)^{\psi_{\pi}}\left(\frac{Y_{t}}{\bar{Y}_{t}}\right)^{\psi_{x}}\right] \frac{M_{t}}{M}
$$


where $i_{t}$ is the short-term nominal interest rate, $\bar{r}_{t}$ is the natural (real) rate of interest, and $\mathbb{E}_{t}\left(\Pi_{t+1}\right)$ is expected (gross) inflation one quarter ahead. Moreover, $\psi_{\pi} \geq 1$ and $\psi_{x} \geq 0$ represent the sensitivity of the monetary policy rule to changes in inflation relative to its target and to the output gap, respectively. $\Pi_{t} \equiv \frac{P_{t}}{P_{t-1}}$ is the (gross) CPI inflation rate and $\frac{\Pi_{t}}{\bar{\Pi}}$ is the corresponding inflation rate in deviations from its steady-state target. $Y_{t}$ denotes the aggregate output produced in the Home country and, accordingly, $\frac{Y_{t}}{\bar{Y}_{t}}$ is the domestic output gap in levels where $\bar{Y}_{t}$ is the corresponding potential output.

What equation (32) means is that the nominal short-term interest rate tracks the natural (real) rate of interest when accounting for inflation expectations and that it responds to inflation deviations from steady state inflation, $\frac{\Pi_{t}}{\bar{\Pi}}$, and to the output gap, $\frac{Y_{t}}{\bar{Y}_{t}}$. Fisher's equation relates the nominal interest rate to the real interest rate and to expected inflation, i.e.,

$$
\left(1+i_{t}\right) \equiv\left(1+r_{t}\right) \mathbb{E}_{t}\left(\Pi_{t+1}\right)
$$

where $r_{t}$ is the real interest rate. It also follows from Fisher's equation that the deterministic steady state real rate $(1+\bar{r})=\beta^{-1}$ and the deterministic steady state nominal interest rate $(1+\bar{i})$ are related by it as $(1+\bar{i}) \equiv(1+\bar{r}) \bar{\Pi}$ where $\bar{\Pi}$ is the (gross) inflation target conventionally set to be equal to the steady-state inflation rate (i.e., $\bar{\Pi}=1$ ). Hence, the monetary policy rule in $(32)$ can be re-expressed in terms of the real interest rate, $r_{t}$, as follows:

$$
\left(\frac{1+r_{t}}{1+\bar{r}}\right)=\left(\frac{1+\bar{r}_{t}}{1+\bar{r}}\right)\left[\left(\frac{\Pi_{t}}{\bar{\Pi}}\right)^{\psi_{\pi}}\left(\frac{Y_{t}}{\bar{Y}_{t}}\right)^{\psi_{x}}\right] \frac{M_{t}}{M} .
$$

The monetary policy index in (32) or that in (34) takes a more conventional form as in Taylor (1993) once it is log-linearized. The monetary policy index for the Foreign country is analogous to (32) or (34).

Conventionally, a specification of monetary policy where the nominal policy rate is explicitly identified as the policy instrument similar to (32) is favored in the literature. The advantage for estimation purposes of doing that is that nominal interest rates are easily observable. The challenges it poses is that it makes it necessary to consider the (occasionally-binding) zero-lower bound constraint on nominal short-term rates explicitly and that it narrows the definition of the monetary policy instruments to that of the policy rate alone. The Home country zero-lower bound constraint can be expressed using Fisher's equation in the following terms:

$$
\left(1+i_{t}\right) \equiv\left(1+r_{t}\right) \mathbb{E}_{t}\left(\Pi_{t+1}\right) \geq 1
$$

In this paper, I prefer to model monetary policy in relation to the real interest rate as 
in (34) because theory itself suggests that the effects of monetary policy on the economy work through fluctuations of the real (not the nominal) interest rate and, therefore, the specification in (34) allows me to remain agnostic about the actual set of policy instruments or tools that the central bank uses to influence the real rate. Moreover, unlike what happens with nominal interest rates, there is no zero-lower bound constraint on the real interest rate. Hence, using Fisher's equation to compute the real interest rate with inflation expectations means that I can implicitly incorporate the impact of the zero-lower bound constraint on the economy without excluding the non-policy-rate tools that the central bank uses (e.g., balance sheet policies, forward guidance) without having to add those features explicitly into the model I want to estimate. As I discuss later, external measures of the current and expected real interest rate formed by private agents that recognize the zero-lower bound constraint and the broad toolkit that central bank deploys can help discipline the model solution to be consistent with those features of monetary policy.

The challenge of working with real rates instead of nominal rates is that they are not directly observable. I rely on survey data for the U.S., but obtaining survey-based measures of the real rate of interest for the rest-of-the-world is a lot more difficult because there are limited sources of survey data for other countries. The reality is that, while in principle it is a worthwhile consideration, in practice I do not observe policy rates to be close to the zerolower bound for the rest-of-the-world aggregate during the sample period of my estimation. Hence, I make the simplifying assumption that monetary policy is effectively unconstrained (as if the Foreign counterpart of (35) could be disregarded) and solve the model adding the Foreign counterpart of the Fisher equation in (35) to tie the unobservable Foreign real rate in the Foreign country counterpart of (34) to the observed Foreign nominal short-term interest rate.

Finally, the Home and Foreign monetary policy shocks, $M_{t}$ and $M_{t}^{*}$, are described by the following exogenous, bivariate stochastic process:

$$
\begin{aligned}
M_{t} & =(M)^{1-\delta_{m}}\left(M_{t-1}\right)^{\delta_{m}} e^{\varepsilon_{t}^{m}} \\
M_{t}^{*} & =(M)^{1-\delta_{m}}\left(M_{t-1}^{*}\right)^{\delta_{m}} e^{\varepsilon_{t}^{m *}} \\
\left(\begin{array}{c}
\varepsilon_{t}^{m} \\
\varepsilon_{t}^{m *}
\end{array}\right) & \sim N\left(\left(\begin{array}{c}
0 \\
0
\end{array}\right),\left(\begin{array}{cc}
\sigma_{m}^{2} & \rho_{m, m^{*}} \sigma_{m}^{2} \\
\rho_{m, m^{*}} \sigma_{m}^{2} & \sigma_{m}^{2}
\end{array}\right)\right),
\end{aligned}
$$

where $M>0$ is its unconditional mean, $-1<\delta_{m}<1$ captures the persistence of the process, and $\left(\varepsilon_{t}^{m}, \varepsilon_{t}^{m *}\right)^{T}$ is a vector of Gaussian innovations with a common variance $\sigma_{m}^{2}>0$ and possibly correlated across both countries $-1<\rho_{m, m^{*}}<1$. Productivity innovations, 
"cost-push" shock innovations, and monetary policy shock innovations can be correlated across countries, but not with each other.

\section{Working with the Equilibrium Conditions}

\subsection{The Zero-Lower Bound on Interest Rates}

The nonlinear system of expectational difference equations that characterizes the solution to the open-economy model described in the previous section can be cast in the following forward-looking canonical form:

$$
\begin{aligned}
f_{Y}\left(Y_{t}, \mathbb{E}_{t}\left(Y_{t+1}\right), X_{t}\right) & =0, \forall t \\
f_{X}\left(X_{t}, X_{t-1}, \varepsilon_{t}\right) & =0, \forall t,
\end{aligned}
$$

where $X_{t}$ is a column-vector of $m>0$ (linearly-independent) exogenous shock processes, $\varepsilon_{t}$ is a column-vector of $m>0$ exogenous shock innovations, and $Y_{t}$ is a column-vector of $n>0$ endogenous variables. Here, $f_{Y}(\cdot)$ is the nonlinear vector function that describes the relationships implied by the first-order conditions of the optimization problems of households and firms together with the corresponding market clearing conditions. The vector function $f_{Y}(\cdot)$ has at least as many equations as there are endogenous variables in $Y_{t}$ and all those equations are binding in every period. The nonlinear vector function $f_{X}(\cdot)$ describes the shock processes of the model and has the same number of equations as there are (linearlyindependent) exogenous shocks in the vector $X_{t}$, all of which hold with equality as well. Apart from satisfying the system of equations in (39) - (40) with equality, the solution must satisfy some occasionally-binding constraints of the following form:

$$
g\left(Y_{t}, \mathbb{E}_{t}\left(Y_{t+1}\right)\right) \geq 0, \forall t
$$

where the vector function $g(\cdot)$ describes the $p>0$ nonlinear but only occasionally-binding constraints of the model, i.e., the zero-lower bound constraint such as the one for the Home country central bank in (35) above.

Let me denote $\tilde{Y}_{t}^{z l b} \equiv\left\{Y_{t}^{z l b}, \mathbb{E}_{t}^{z l b}\left(Y_{t+1}^{z l b}\right)\right\}$ the solution to the constrained system given by $(39)-(40)$ and (41) for a given set of initial conditions. In here, $\tilde{Y}_{t}^{z l b}$ contains not just the path of the endogenous variables subject to occasionally-binding constraints, $Y_{t}^{z l b}$, but also their expectations, $\mathbb{E}_{t}^{z l b}\left(Y_{t+1}^{z l b}\right)$. While solving the model with occasionally-binding 
constraints such as those in (41) has its challenges, I posit that if $\widetilde{Y}_{t}^{z l b}$ is observable, then it suffices to estimate the model with equations $(39)-(40)$ alone. If indeed $\tilde{Y}_{t}^{z l b}$ is observable, the system of equations needed for estimation would simply be:

$$
\begin{aligned}
f_{Y}\left(Y_{t}^{z l b}, \mathbb{E}_{t}^{z l b}\left(Y_{t+1}^{z l b}\right), X_{t}\right) & =0, \forall t \\
f_{X}\left(X_{t}, X_{t-1}, \varepsilon_{t}\right) & =0, \forall t .
\end{aligned}
$$

In other words, estimation does not require the use of the full system of equations that includes the occasionally-binding constraints (the zero-lower bound constraints) in (41) so long as the observed data including the expectations is already shaped by the private agents' and policymaker's response to those occasionally-binding constraints. Using observed data on expectations for estimation purposes means that a subset of the equilibrium conditions of the model that does not explicitly include (41) can be estimated because observed expectations bind the solution to conform with the impact of occasionally-binding constraints as reflected on the decisions and expectations of private agents and policymakers. ${ }^{4}$

Adding survey data on expectations to the observable set rather than augmenting the equilibrium conditions in (39) - (40) with equation (41) is all that is needed to obtain estimates consistent with the zero-lower bound constraint given that those expectations internalize the expected path of an economy that can occasionally become constrained by the zero-lower bound on the policy rate. ${ }^{5}$ What would be the problem if I were to use $Y_{t}^{z l b}$ instead of $\widetilde{Y}_{t}^{z l b}$ as my observables in order to estimate a system like that in (42) - (43)? The problem is that, unless expectations are disciplined by the data to be consistent with the zero-lower bound constraint, the model expectations will be formed endogenously with no constraint to enforce the zero-lower bound on policy rates. That, therefore, can distort the estimation and empirical inferences because the estimated model wants to fit an unconstrained solution on the observable data $Y_{t}^{z l b}$ that is known to arise from a data-generating process constrained by the zero-lower bound. In turn, taking expectations as exogenously given when observable circumvents this issue without the need of adding (41) because those expectations have already been shaped by private agents and policymakers that are aware of the zero-lower bound and that have internalized the likelihood and duration of zero-lower bound episodes

\footnotetext{
${ }^{4}$ I should note here also that using survey data means that the estimation can also be agnostic about whether expectations are formed by fully-informed rational expectations (FIRE) or not.

${ }^{5}$ Private agents and policymakers also must form expectations about the exogenous variables, e.g., about productivity shocks. The rationale here is that the zero-lower bound constraint does not affect their expectations about exogenous variables such as productivity, it only would affect their expectations of how the economy endogenously responds to those exogenous shocks. For that reason, only the expectations of the endogenous variables need to be tracked when applying this approach to estimate the model.
} 
in their views about the future state of the economy.

Using survey data is not always possible given its limited availability and that can be a particular concern in open-economy models such as the one I investigate here. Given that my model develops a two-country setup for the U.S. (Home country) and for a trade-weighted aggregate of its major trading partners (Foreign country) where only the former (the U.S.) hits the zero-lower bound in-sample while the latter (the rest-of-the-world aggregate) is characterized by short-term interest rates well above zero over the entire sample period, I approximate the model solution with the solution unconstrained by the Foreign country zero-lower-bound in estimating (42) - (43).

Hence, I use survey data for the Home country (U.S.) variables to discipline the model estimates and inferences to be consistent with the zero-lower bound experience in the U.S., as U.S. macro forecasts are readily available. However, I let expectations for the rest-of-theworld aggregate to be determined endogenously. This has the practical advantage that it does not require me to obtain survey data for all countries in the rest-of-the-world aggregate which would be difficult to acquire. I believe this approach which uses survey data only on U.S. macro expectations has only marginal effects on the estimation. After all, as I discussed in the previous section, the rest-of-the-world aggregate is far away from the zerolower bound, so the likelihood of a zero-lower-bound episode in the Foreign country is rather tiny and, accordingly, the constrained Foreign outcome path must be close to the Foreign unconstrained one anyway.

Given the evidence available in my sample, approximating the constrained solution with the unconstrained one for the rest-of-the-world aggregate economy appears reasonable as I do not expect this would introduce significant distortions in the estimation. In what follows, I adopt this approach and henceforth drop the superscript $z l b$ for ease of notation.

\subsection{The Log-Linear Equilibrium Conditions}

The canonical system of equations described in (42) - (43) is nonlinear. Here, I use for the estimation a log-linearization of those equilibrium conditions around the deterministic, zero-inflation steady state. The log-linearization of (42) - (43) is fairly straightforward and its akin to that explored in greater detail by Martínez-García and Wynne (2010), MartínezGarcía et al. (2012), Martínez-García and Wynne (2014), Martínez-García (2015), and Martínez-García (2019). For that reason, I refer the interested reader to those sources for the derivation of the main log-linearized equations and instead concentrate here on how to accommodate the data to estimate those log-linearized equilibrium conditions. 


\subsubsection{Main Equilibrium Conditions of the Structural Model}

The main equilibrium conditions of the workhorse open-economy New Keynesian model are log-linearized around a deterministic, zero-inflation steady-state and summarized in Table 1 and Table 2. The deterministic steady state with zero inflation (i.e., with gross inflation at $\bar{\Pi}=1$ ) satisfies that $(1+\bar{i})=(1+\bar{r}) \bar{\Pi}=\frac{1}{\beta}>1$, given that $0<\beta<1$, where $\bar{i}$ and $\bar{r}$ are the nominal and real interest rates in steady state, respectively. In other words, the zero-lower bound constraint can be occasionally-binding during the transition towards the deterministic steady state but it is non-binding in the deterministic, zero-inflation steady state itself.

I denote $\widehat{z}_{t} \equiv \ln \left(\frac{Z_{t}}{\bar{Z}}\right)$ the deviation of a given variable in logs from its steady state. I define a vector of endogenous variables in log-deviations from steady state, $\widehat{Y}_{t}$, a vector of exogenous variables in log-deviations from steady state, $\widehat{X}_{t}$, and a vector of exogenous shock innovations also in log-deviations from steady state, $\widehat{\varepsilon}_{t}$. Hence, the log-linearized approximation of $(42)-(43)$ can be cast in its linear form as:

$$
\begin{aligned}
M \widehat{Y}_{t} & =N \mathbb{E}_{t}\left(\widehat{Y}_{t+1}\right)+Q \widehat{X}_{t}, \forall t \\
\widehat{X}_{t} & =A \widehat{X}_{t-1}+B \widehat{\varepsilon}_{t}, \forall t
\end{aligned}
$$

where $M, N, Q, A$, and $B$ are conforming matrices. This specification is also supplemented with the following auxiliary equations:

$$
\begin{aligned}
\widehat{Y}_{t}^{o} & =H_{Y_{1}} \widehat{Y}_{t}+H_{Y_{2}} \mathbb{E}_{t}\left(\widehat{Y}_{t+1}\right)+H_{X} \widehat{X}_{t}, \forall t, \\
\mathbb{E}_{t}^{\text {survey }}\left(\widehat{Y}_{t+1}^{g}\right) & =\mathbb{E}_{t}\left(\widehat{Y}_{t+1}^{g}\right)+\widehat{o}_{t}, \forall t
\end{aligned}
$$

where $\widehat{\widetilde{Y}}_{t}^{o} \equiv\left\{\widehat{Y}_{t}^{o}, \mathbb{E}_{t}^{\text {survey }}\left(\widehat{Y}_{t+1}^{g}\right)\right\}$. Here, $\widehat{Y}_{t}^{o}$ is a vector of other endogenous variables not included in $\widehat{Y}_{t}$ that can be described as a linear mapping of $\left\{\widehat{Y}_{t}, \mathbb{E}_{t}\left(\widehat{Y}_{t+1}\right), \widehat{X}_{t}\right\} \cdot \mathbb{E}_{t}^{\text {survey }}\left(\widehat{Y}_{t+1}^{g}\right)$ is a vector of the survey data on expectations for some or all of the endogenous variables of the model, that is, for $\widehat{Y}_{t}^{g} \subseteq\left\{\widehat{Y}_{t}, \widehat{Y}_{t}^{o}\right\} . \mathbb{E}_{t}^{\text {survey }}\left(\widehat{Y}_{t+1}^{g}\right)$ is set to be equal to the vector of endogenous expectation counterparts $\mathbb{E}_{t}\left(\widehat{Y}_{t+1}^{g}\right)$ allowing for some measurement error $\widehat{o}_{t}$ in the form of i.i.d. (uncorrelated) white noise. Finally, I define the vector of observables as $\widehat{\widetilde{Y}}_{t}^{\text {obs }} \equiv\left\{\widehat{Y}_{t}^{\text {obs }}, \mathbb{E}_{t}^{\text {survey }}\left(\widehat{Y}_{t+1}^{g}\right)\right\}$ where $\widehat{Y}_{t}^{\text {obs }} \subseteq\left\{\widehat{Y}_{t}, \widehat{Y}_{t}^{o}, \widehat{X}_{t}\right\}$.

As laid out in Table 1 and Table 2, the core endogenous variables of the model include: $\widehat{\pi}_{t}$ and $\widehat{\pi}_{t}^{*}$ which denote Home and Foreign inflation (quarter-over-quarter changes in the 
consumption-based price index) respectively, $\widehat{x}_{t}$ and $\widehat{x}_{t}^{*}$ which define the Home and Foreign output gaps (deviations of output from its frictionless level), and $\widehat{r}_{t}$ and $\widehat{r}_{t}^{*}$ which are the Home and Foreign one-period real interest rates. The exogenous variables include three types of country-specific, exogenous shocks: Home and Foreign productivity shocks, $\widehat{a}_{t}$ and $\widehat{a}_{t}^{*}$, Home and Foreign "cost-push" shocks, $\widehat{u}_{t}$ and $\widehat{u}_{t}^{*}$, and Home and Foreign monetary policy shocks (shocks to the Taylor (1993) rule), $\widehat{m}_{t}$ and $\widehat{m}_{t}^{*}$.

Apart from that, Table 1 also describes the frictionless equilibrium (potential) allocation that arises under flexible prices and under perfect competition in the markets for goods and labor. I denote $\widehat{\bar{z}}_{t} \equiv \ln \left(\frac{\bar{Z}_{t}}{\bar{Z}}\right)$ the deviation of an endogenous potential variable in logs from its steady-state value. ${ }^{6}$ The frictionless model and the benchmark model are subject to the same realization of each of the exogenous shocks. It follows from the characterization of the frictionless model that neither the monetary policy rule nor monetary shocks have an impact on any of the real variables of the model (i.e., they don't have an impact on either potential output or the natural (real) interest rate). Moreover, because monetary policy neutrality holds both in the short- and long-run in the frictionless case, the zero-lower bound on the nominal interest rate is also irrelevant to determine output potential and the natural rate of interest. In other words, the zero-lower bound only affects the short-run dynamics in the presence of nominal rigidities.

"Cost-push" shocks also drop out whenever prices are set in perfectly competitive goods markets with flexible prices and that's why only productivity shocks affect the frictionless allocation. The natural rates, $\widehat{\bar{r}}_{t}$ and $\widehat{\bar{r}}_{t}^{*}$, are expressed as a function of expected changes in Home and Foreign potential output growth. Potential output for each country, $\widehat{\bar{y}}_{t}$ and $\widehat{\bar{y}}_{t}^{*}$, is a function of the Home and Foreign productivity shocks alone, $\widehat{a}_{t}$ and $\widehat{a}_{t}^{*}$. By extension, the natural rate in each country is determined by the dynamics of productivity and, due to openness to trade, that involves both Home and Foreign productivity. ${ }^{7}$ In fact, as seen in Table 1, productivity shocks enter into the model dynamics only through their impact on the dynamics of the natural rates, $\widehat{\bar{r}}_{t}$ and $\widehat{\bar{r}}_{t}^{*}$, and on the dynamics of the potential output, $\widehat{\bar{y}}_{t}$ and $\widehat{\bar{y}}_{t}^{*}$, in the frictionless equilibrium.

\footnotetext{
${ }^{6}$ Under the assumption that each country's government implements an optimal labor subsidy to remove the price mark-up distortions in equilibrium which I have discussed in the previous section, the steady state of the frictionless and benchmark models is identical.

${ }^{7}$ The natural rates do not necessarily equalize across countries because Home-product bias in consumption implies different consumption baskets for the Home and Foreign countries and that generally prevents crosscountry equalization in response to shocks that are, by their very own nature, country-specific. To be precise, in a knife-edge situation where both the Home and Foreign households' share of domestic and imported goods coincides with the share of locally-produced goods which is $\frac{1}{2}$ in the model, the Home and Foreign natural rates would equalize.
} 
Finally, the basic structure of the two-country New Keynesian model with monopolistic competition in prices and with staggered price setting à la Calvo (1983) given in Table 1 and Table 2 provides a tractable open-economy environment under monetary non-neutrality, subject to country-specific shocks. It should be noted that the basic structure provided by the equilibrium conditions of the model in Table 1 describes the dynamics of the two-country economy with three equations for each country: an open-economy Phillips curve, an openeconomy dynamic IS equation, and a Wicksellian-type Taylor (1993) rule for monetary policy. This workhorse open-economy model nests the three-equation, closed-economy case when the import share $\xi$ is set to zero. ${ }^{8}$ In general terms, the rationale for each of the constituent parts of the model is:

- The open-economy Phillips curve is an equilibrium condition that fleshes out the global slack hypothesis, that is, the idea that in a world open to trade, the relevant trade-off for monetary policy is between local inflation and global (rather than local) slack. MartínezGarcía (2019) provides further discussion on the open-economy Phillips curve and its role in the model.

- The open-economy IS equation ties the evolution of the output gap (the deviation of actual output from its frictionless potential) to both Home and Foreign demand through the real interest rate wedge of both countries. Nominal rigidities introduce an intertemporal wedge between the actual real interest rate (the opportunity cost of consumption today versus consumption tomorrow) and the natural (real) rate of interest (the opportunity cost of consumption today versus consumption tomorrow in an economy where all frictions are absent). ${ }^{9}$

○ The Home and Foreign monetary policy rules complete the specification. Monetary policy is modeled with a Wicksellian-type Taylor (1993) rule that tracks the local natural rate of interest and reacts to local conditions as determined by the country's inflation deviations from steady state and by the output gap.

\footnotetext{
${ }^{8}$ This framework can be generalized to include backward-looking terms as well. For a method to solve linear rational expectations models with backward-looking and forward-looking terms, see Martínez-García (2020a).

${ }^{9}$ Aggregate demand deviates from aggregate demand in the frictionless equilibrium whenever each country's real interest rate deviates from its natural (real) rate inducing differences between the consumption patterns in the benchmark and the frictionaless cases at a given point in time. That, in turn, induces deviations of output from its potential.
} 


\section{Table 1 - Open-Economy New Keynesian Model}

\section{Home Economy}

\begin{tabular}{|c|c|}
\hline Phillips curve & $\widehat{\pi}_{t} \approx \beta \mathbb{E}_{t}\left(\widehat{\pi}_{t+1}\right)+\Phi(\varphi+\gamma)\left[\kappa \widehat{x}_{t}+(1-\kappa) \widehat{x}_{t}^{*}+(1-\xi) \widehat{u}_{t}+\xi \widehat{u}_{t}^{*}\right]$ \\
\hline Dynamic IS equation & $\gamma\left(\mathbb{E}_{t}\left(\widehat{x}_{t+1}\right)-\widehat{x}_{t}\right) \approx \Omega\left[\widehat{i}_{t}-\mathbb{E}_{t}\left(\widehat{\pi}_{t+1}\right)-\widehat{\bar{r}}_{t}\right]+(1-\Omega)\left[\widehat{i}_{t}^{*}-\mathbb{E}_{t}\left(\widehat{\pi}_{t+1}^{*}\right)-\widehat{\bar{r}}_{t}^{*}\right]$ \\
\hline Monetary policy & $\widehat{i}_{t} \approx \widehat{\bar{r}}_{t}+\mathbb{E}_{t}\left(\widehat{\pi}_{t+1}\right)+\psi_{\pi} \widehat{\pi}_{t}+\psi_{x} \widehat{x}_{t}+\widehat{m}_{t}$ \\
\hline Natural interest rate & $\widehat{\bar{r}}_{t} \approx \gamma\left[\Theta\left(\mathbb{E}_{t}\left(\widehat{\bar{y}}_{t+1}\right)-\widehat{\bar{y}}_{t}\right)+(1-\Theta)\left(\mathbb{E}_{t}\left(\widehat{\bar{y}}_{t+1}^{*}\right)-\widehat{\bar{y}}_{t}^{*}\right)\right.$ \\
\hline Potential output & $\widehat{\bar{y}}_{t} \approx\left(\frac{1+\varphi}{\gamma+\varphi}\right)\left[\Lambda \widehat{a}_{t}+(1-\Lambda) \widehat{a}_{t}^{*}\right]$ \\
\hline Production function & $\widehat{y}_{t} \approx \widehat{a}_{t}+\widehat{l}_{t}$ \\
\hline Output definition & $\widehat{y}_{t} \equiv \widehat{\bar{y}}_{t}+\widehat{x}_{t}$ \\
\hline Fisher equation & $\widehat{i}_{t} \approx \widehat{r}_{t}+\mathbb{E}_{t}\left(\widehat{\pi}_{t+1}\right)$ \\
\hline
\end{tabular}

\section{Foreign Economy}

Phillips curve $\quad \widehat{\pi}_{t}^{*} \approx \beta \mathbb{E}_{t}\left(\widehat{\pi}_{t+1}^{*}\right)+\Phi(\varphi+\gamma)\left[(1-\kappa) \widehat{x}_{t}+\kappa \widehat{x}_{t}^{*}+\xi \widehat{u}_{t}+(1-\xi) \widehat{u}_{t}^{*}\right]$

Dynamic IS equation $\gamma\left(\mathbb{E}_{t}\left(\widehat{x}_{t+1}^{*}\right)-\widehat{x}_{t}^{*}\right) \approx(1-\Omega)\left[\widehat{i}_{t}-\mathbb{E}_{t}\left(\widehat{\pi}_{t+1}\right)-\widehat{\bar{r}}_{t}\right]+\Omega\left[\widehat{i}_{t}^{*}-\mathbb{E}_{t}\left(\widehat{\pi}_{t+1}^{*}\right)-\widehat{\bar{r}}_{t}^{*}\right]$

Monetary policy $\widehat{i}_{t}^{*} \approx \widehat{\bar{r}}_{t}^{*}+\mathbb{E}_{t}\left(\widehat{\pi}_{t+1}^{*}\right)+\psi_{\pi} \widehat{\pi}_{t}^{*}+\psi_{x} \widehat{x}_{t}^{*}+\widehat{m}_{t}^{*}$

Natural interest rate

$$
\widehat{\bar{r}}_{t}^{*} \approx \gamma\left[(1-\Theta)\left(\mathbb{E}_{t}\left(\widehat{\bar{y}}_{t+1}\right)-\widehat{\bar{y}}_{t}\right)+\Theta\left(\mathbb{E}_{t}\left(\widehat{\bar{y}}_{t+1}^{*}\right)-\widehat{\bar{y}}_{t}^{*}\right)\right]
$$

Potential output $\widehat{\bar{y}}_{t}^{*} \approx\left(\frac{1+\varphi}{\gamma+\varphi}\right)\left[(1-\Lambda) \widehat{a}_{t}+\Lambda \widehat{a}_{t}^{*}\right]$

Production function

Output definition

$$
\widehat{y}_{t}^{*} \approx \widehat{a}_{t}^{*}+\widehat{l}_{t}^{*}
$$

Fisher equation

$$
\begin{gathered}
\widehat{y}_{t}^{*} \equiv \widehat{\bar{y}}_{t}^{*}+\widehat{x}_{t}^{*} \\
\hat{i}_{t}^{*} \approx \widehat{r}_{t}^{*}+\mathbb{E}_{t}\left(\widehat{\pi}_{t+1}^{*}\right)
\end{gathered}
$$

\section{Composite Parameters}

$$
\begin{aligned}
\Omega & \equiv(1-\xi)\left[\frac{1-2 \xi(1-\sigma \gamma)}{1-2 \xi}\right], \Theta \equiv(1-\xi)\left[\frac{1+(\sigma \gamma-1)(2 \xi)}{1+(\sigma \gamma-1)(2 \xi)(2(1-\xi))}\right] \\
\Phi & \equiv\left(\frac{(1-\alpha)(1-\beta \alpha)}{\alpha}\right), \Lambda \equiv 1+\frac{1}{2}\left[\frac{\left(\frac{\gamma}{\varphi+\gamma}\right)(\sigma \gamma-1)(2 \xi)(2(1-\xi))}{1+\left(1-\frac{\gamma}{\varphi+\gamma}\right)(\sigma \gamma-1)(2 \xi)(2(1-\xi))}\right] \\
\kappa & \equiv(1-\xi)\left[1-(\sigma \gamma-1)\left(\frac{\gamma}{\varphi+\gamma}\right)\left(\frac{(2 \xi)(1-2 \xi)}{1+(\sigma \gamma-1)(2 \xi)(2(1-\xi))}\right)\right]
\end{aligned}
$$




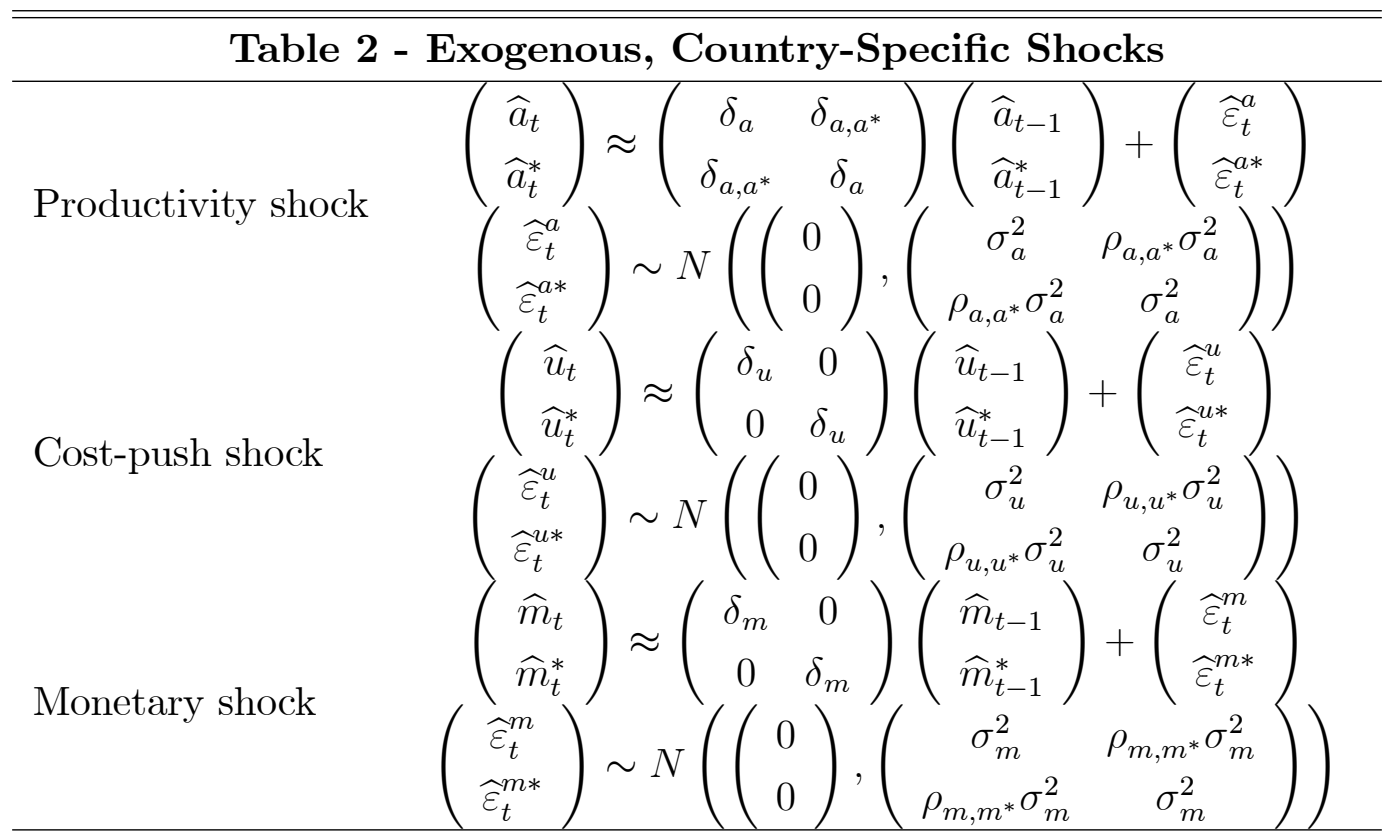

The productivity shocks, $\widehat{a}_{t}$ and $\widehat{a}_{t}^{*}$, enter into the model solely through the potential output, $\widehat{\bar{y}}_{t}$ and $\widehat{\bar{y}}_{t}^{*}$, and through the natural rates of interest, $\widehat{\bar{r}}_{t}$ and $\widehat{\bar{r}}_{t}^{*}$, in Table 1 . Combining the equations that describe potential output in both countries with those for the natural rate, it follows that the natural rate can be re-expressed in terms of Home and Foreign productivity growth as:

$$
\begin{aligned}
& \widehat{\bar{r}}_{t} \approx \gamma\left(\frac{1+\varphi}{\gamma+\varphi}\right)\left[\begin{array}{c}
(\Theta \Lambda+(1-\Theta)(1-\Lambda))\left(\mathbb{E}_{t}\left[\widehat{a}_{t+1}\right]-\widehat{a}_{t}\right)+\ldots \\
(1-(\Theta \Lambda+(1-\Theta)(1-\Lambda)))\left(\mathbb{E}_{t}\left[\widehat{a}_{t+1}^{*}\right]-\widehat{a}_{t}^{*}\right)
\end{array}\right], \\
& \widehat{\bar{r}}_{t}^{*} \approx \gamma\left(\frac{1+\varphi}{\gamma+\varphi}\right)\left[\begin{array}{c}
(1-(\Theta \Lambda+(1-\Theta)(1-\Lambda)))\left(\mathbb{E}_{t}\left[\widehat{a}_{t+1}\right]-\widehat{a}_{t}\right)+\ldots \\
(\Theta \Lambda+(1-\Theta)(1-\Lambda))\left(\mathbb{E}_{t}\left[\widehat{a}_{t+1}^{*}\right]-\widehat{a}_{t}^{*}\right)
\end{array}\right],
\end{aligned}
$$

where the composite coefficients $\Theta$ and $\Lambda$ are described in Table 1 . In the case where preferences are autarkic and the steady state import share $\xi$ is set to zero, then the natural rate of interest in a country is proportional to the expected productivity growth, i.e., $\widehat{\bar{r}}_{t} \approx$ $\gamma\left(\frac{1+\varphi}{\gamma+\varphi}\right)\left(\mathbb{E}_{t}\left[\widehat{a}_{t+1}\right]-\widehat{a}_{t}\right)$ and $\widehat{\bar{r}}_{t}^{*} \approx \gamma\left(\frac{1+\varphi}{\gamma+\varphi}\right)\left(\mathbb{E}_{t}\left[\widehat{a}_{t+1}^{*}\right]-\widehat{a}_{t}^{*}\right)$. Here, the scaling factor $\gamma\left(\frac{1+\varphi}{\gamma+\varphi}\right)$ depends solely on the inverse of the intertemporal elasticity of substitution $\gamma>0$ and the inverse of the Frisch elasticity of labor supply $\varphi>0$. However, when households have preferences over Foreign as well as Home varieties (i.e., when $0<\xi<1$ ), it is no longer necessarily the case that a decline in the Home natural rate is the result of a slowdown in Home productivity as this would be influenced by Foreign productivity growth as well. 
In equations (48) - (49), apart from the same preference parameters $\gamma>0$ and $\varphi>0$, the weights on Home and productivity growth depend also on two additional preference parameters related to the "trade channel" in the model: the import share parameter $0<$ $\xi<1$ itself and the elasticity of substitution between home and Foreign goods (that is, the trade elasticity) $\sigma>0$. Implicitly, these four preference parameters can be described also with $\gamma, \xi$, and the composites $\left(\frac{\gamma}{\gamma+\varphi}\right)$, and $\sigma \gamma$. To illustrate the direct effect of Home and Foreign expected productivity growth, Figure 1 plots the weights that linearly map the Home and Foreign productivity growth into the Home natural rate given by equation (48) scaled by $\gamma\left(\frac{1+\varphi}{\gamma+\varphi}\right)$. Given the standard parameterization of $\gamma=2$ used by Martínez-García (2020b), the scaled weights are plotted over a grid of points for plausible values in the parameter space for $\xi,\left(\frac{\gamma}{\gamma+\varphi}\right)$, and $\sigma \gamma \cdot{ }^{10}$

One can see from the top panel of Figure 1 that, given $\gamma$ and $\varphi$, the magnitude of these weights varies with the degree of openness, $\xi$, and with the trade elasticity, $\sigma$. In the case where $\sigma \gamma=1$, the weight of Home productivity growth on the Home natural rate declines linearly with the import share $\xi$ while the weight of Foreign productivity increases linearly with the import share. However, it is not just the import share $\xi$ but other trade-related parameters of the model like the trade elasticity $\sigma$ (which captures the strength of endogenous cross-country propagation in the model) that matter. An important implication is that the weight on Foreign productivity growth is larger (and correspondingly the weight on Home productivity growth smaller) when $\sigma \gamma>1$ than in the knife-edge case where $\sigma \gamma=1$. The opposite holds true whenever $0<\sigma \gamma<1$. Hence, the trade elasticity $\sigma$ plays a crucial role that can result in Foreign productivity growth becoming more prominent in driving the path of the natural rate of interest than the degree of openness implied by $\xi$ would otherwise suggest.

Assuming productivity shocks follow the stationary bivariate $\operatorname{VAR}(1)$ process posited in Table 2, then the natural rate of interest can be expressed in terms of the Home and Foreign productivity in levels as follows:

$$
\begin{aligned}
& \widehat{\bar{r}}_{t} \approx \gamma\left(\frac{1+\varphi}{\gamma+\varphi}\right)\left[\begin{array}{r}
\left((\Theta \Lambda+(1-\Theta)(1-\Lambda))\left(\delta_{a}-1\right)+(1-(\Theta \Lambda+(1-\Theta)(1-\Lambda))) \delta_{a, a^{*}}\right) \widehat{a}_{t}+\ldots \\
\left((\Theta \Lambda+(1-\Theta)(1-\Lambda)) \delta_{a, a^{*}}+(1-(\Theta \Lambda+(1-\Theta)(1-\Lambda)))\left(\delta_{a}-1\right)\right) \widehat{a}_{t}^{*}
\end{array}\right] 0,0_{0} \\
& \left.\widehat{\bar{r}}_{t}^{*} \approx \gamma\left(\frac{1+\varphi}{\gamma+\varphi}\right)\left[\begin{array}{c}
\left((\Theta \Lambda+(1-\Theta)(1-\Lambda)) \delta_{a, a^{*}}+(1-(\Theta \Lambda+(1-\Theta)(1-\Lambda)))\left(\delta_{a}-1\right)\right) \widehat{a}_{t}+\ldots \\
\left((\Theta \Lambda+(1-\Theta)(1-\Lambda))\left(\delta_{a}-1\right)+(1-(\Theta \Lambda+(1-\Theta)(1-\Lambda))) \delta_{a, a^{*}}\right) \widehat{a}_{t}^{*}
\end{array}\right] 1 .\right)
\end{aligned}
$$

\footnotetext{
${ }^{10}$ Although Figure 1 plots only the weights for the Home natural rate of interest, the Foreign natural rate is symmetric and therefore the features of the plot apply equally in the foreign economy.
} 
Figure A1. The Weights on the Domestic Natural Rate

\section{A. Weights of Domestic and Foreign Productivity Growth}
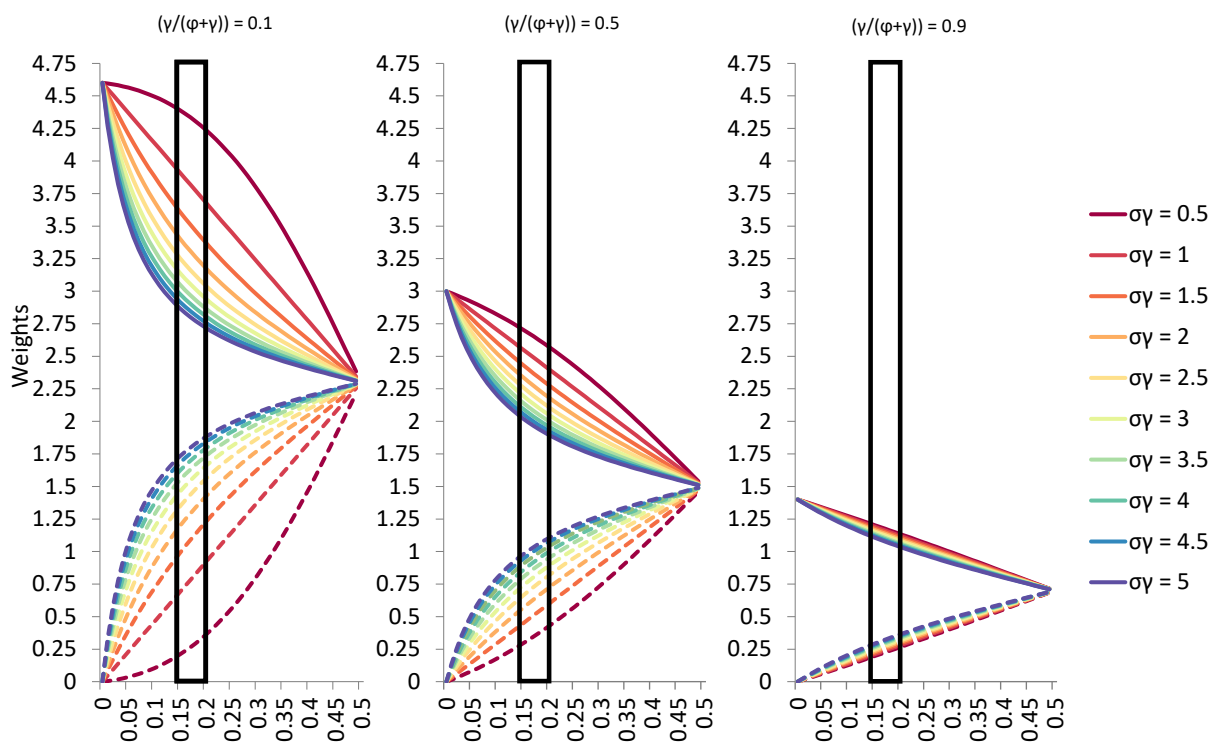

\section{B. Weights of Domestic and Foreign Productivity Levels}

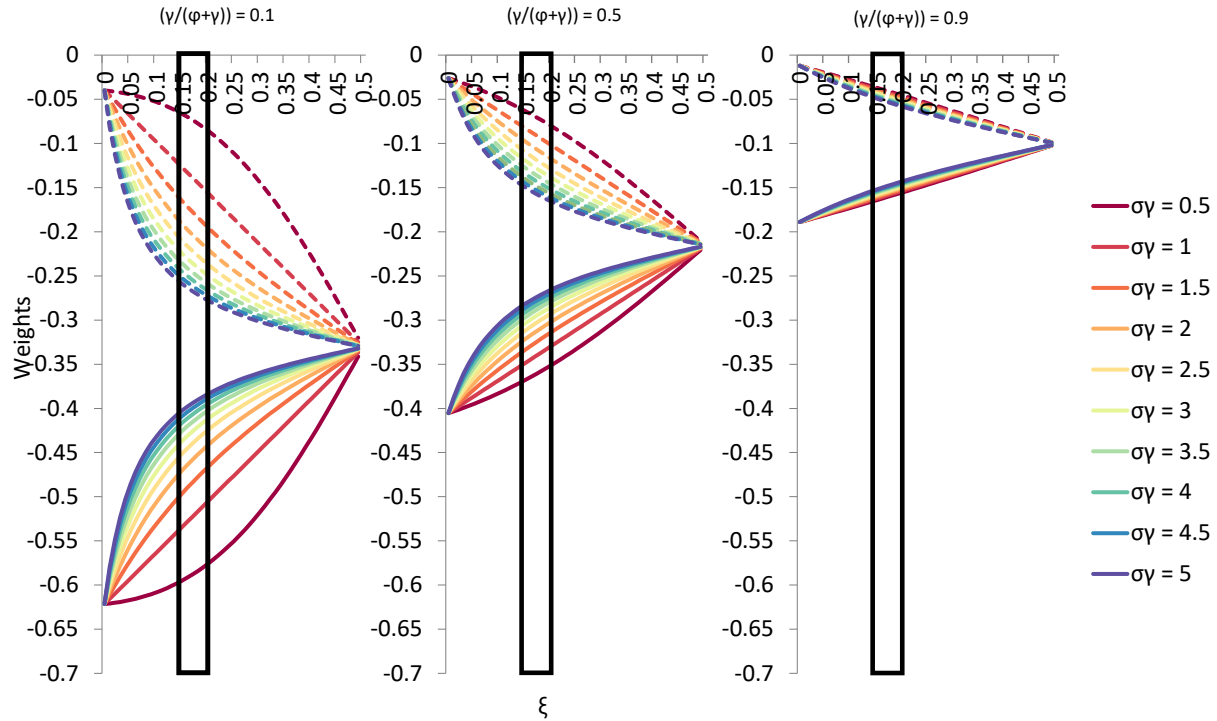

This figure plots the corresponding composite coefficients for the prior means parameterization reported in Martínez-García (2020b). The dotted lines represent the composite coefficient on foreign productivity while the solid lines are the corresponding composite coefficient on domestic productivity. The bar with black margins indicates the range of the import share that would be most consistent with the U.S. import share. I use Matlab 7.13.0.564 and Dynare v4.2.4 for the stochastic simulation that produces these results. 
What these formulas show is that the impact and even the sign of a productivity shock is going to depend on the structure of the productivity shock process. In particular, it depends on the persistence of the productivity shock, $\delta_{a}$, but also on the technological diffusion parameter, $\delta_{a, a^{*}}$. Whenever there is no technological diffusion across countries and $\delta_{a, a^{*}}=0$, then it easily follows that equations (50) - (51) that a higher productivity (either Home or Foreign) lowers the natural rate of interest given that the persistence parameter must satisfy that $\delta_{a}<1$. Whenever technological diffusion is a feature of the economy, an increase in Foreign productivity can either raise or lower the Home natural rate depending on the sign and magnitude of the parameter $\delta_{a, a^{*}}$ as this exogenous feature influences decidedly the cross-country propagation of the productivity shocks. In fact, it is plausible that for certain values of $\delta_{a, a^{*}}$ the contribution of the Foreign shocks may be close to zero as can be seen in the bottom panel of Figure 1.

If the economy is in fact open as postulated by the model, but the trade-related parameters lie within the range of plausible values indicated by the black bars in Figure 1, then Foreign productivity may have little effect on the determination of the Home natural rate which then becomes not too dissimilar from the closed-economy $(\xi=0)$ natural rate. ${ }^{11}$ The equations in $(50)$ - (51) together with the $\operatorname{VAR}(1)$ specification for the productivity shocks introduced in Table 2 can be used to show the deep linkages between the exogenous productivity shock process and the model-consistent natural rates of interest. As can be seen in the following proposition, the analytical solution of the natural rate for both countries can be characterized and inherits some of its properties from the VAR(1) structure of the productivity shock process. Structural preference parameters only influence the variance-covariance structure as follows:

Proposition 1 The natural rates of interest in (50)-(51) inherit the dynamics and features of the productivity shock process in Table 2 and behave as a VAR(1) process of the following

\footnotetext{
${ }^{11}$ I should also note that other features of the economy not directly related to trade openness can have a sizeable effect on our interpretation of the role that the "trade channel" and cross-country technological diffusion play on the natural rate. For instance, the inverse of the Frisch elasticity of labor supply, $\varphi$, captures an important aspect of how local labor markets operate. In this two-country model, the Frisch elasticity parameterization has undoubtedly a major impact on the magnitudes of the effects on the natural rate, as can be judged in Figure 1.
} 
form:

$$
\begin{aligned}
& \left(\begin{array}{c}
\widehat{\bar{r}}_{t} \\
\widehat{\bar{r}}_{t}^{*}
\end{array}\right) \approx\left(\begin{array}{cc}
\delta_{a} & \delta_{a, a^{*}} \\
\delta_{a, a^{*}} & \delta_{a}
\end{array}\right)\left(\begin{array}{c}
\widehat{\bar{r}}_{t-1} \\
\widehat{\bar{r}}_{t-1}^{*}
\end{array}\right)+\left(\begin{array}{c}
\widehat{\varepsilon}_{t}^{r} \\
\widehat{\varepsilon}_{t}^{r *}
\end{array}\right), \\
& \left(\begin{array}{c}
\widehat{\varepsilon}_{t}^{r} \\
\widehat{\varepsilon}_{t}^{r *}
\end{array}\right) \sim N\left(\left(\begin{array}{c}
0 \\
0
\end{array}\right),\left(\begin{array}{cc}
\sigma_{r}^{2} & \rho_{r, r^{*}} \sigma_{r}^{2} \\
\rho_{r, r^{*}} \sigma_{r}^{2} & \sigma_{r}^{2}
\end{array}\right)\right),
\end{aligned}
$$

where

$$
\begin{aligned}
\sigma_{r}^{2} & \equiv \sigma_{a}^{2} \gamma^{2}\left(\frac{1+\varphi}{\gamma+\varphi}\right)^{2}\left(\left(\Pi_{1}\right)^{2}+2 \rho_{a, a^{*}} \Pi_{1} \Pi_{2}+\left(\Pi_{2}\right)^{2}\right), \\
\rho_{r, r^{*}} & \equiv \frac{\rho_{a, a^{*}}\left(\Pi_{1}\right)^{2}+2 \Pi_{1} \Pi_{2}+\rho_{a, a^{*}}\left(\Pi_{2}\right)^{2}}{\left(\Pi_{1}\right)^{2}+2 \rho_{a, a^{*}} \Pi_{1} \Pi_{2}+\left(\Pi_{2}\right)^{2}},
\end{aligned}
$$

and

$$
\begin{aligned}
\Pi_{1} & \equiv \delta_{a, a^{*}}-(1-\xi)\left(\frac{1+\left(1-\frac{\gamma}{\varphi+\gamma}\right)(\sigma \gamma-1)(2 \xi)}{1+\left(1-\frac{\gamma}{\varphi+\gamma}\right)(\sigma \gamma-1)(2 \xi)(2(1-\xi))}\right)\left(\delta_{a, a^{*}}+1-\delta_{a}\right), \quad(56) \\
\Pi_{2} & \equiv\left(\delta_{a}-1\right)+(1-\xi)\left(\frac{1+\left(1-\frac{\gamma}{\varphi+\gamma}\right)(\sigma \gamma-1)(2 \xi)}{1+\left(1-\frac{\gamma}{\varphi+\gamma}\right)(\sigma \gamma-1)(2 \xi)(2(1-\xi))}\right)\left(\delta_{a, a^{*}}+1-\delta_{a}\right)(, 57)
\end{aligned}
$$

define the volatility and the correlation of the corresponding natural rate innovations.

This result follows after some tedious algebra once one recognizes that (50) - (51) is just a linear mapping of the vector of productivity shocks $\left(\widehat{a}_{t}, \widehat{a}_{t}^{*}\right)$ into the vector of natural

rates $\left(\widehat{\bar{r}}_{t}, \widehat{r}_{t}^{*}\right)$. Notice that not only the persistence and cross-country spillover parameters, $\delta_{a}$ and $\delta_{a, a^{*}}$ respectively, are inherited by the stochastic process for the natural rates, but they also enter into the natural rate variance-covariance structure described by (54) - (57). This shows also the inherent difficulties associated with identifying and interpreting the role of the "trade channel" on the natural rate and, therefore, illustrates the potential for weak identification problems to arise in bringing the workhorse open-economy New Keynesian model to the data.

\subsubsection{Expectations-Augmented Equilibrium Conditions}

Here I describe in four simple steps how the equilibrium conditions summarized in Table 1 and Table 2 are adapted for the estimation when the vector of observables includes macro 
variables and survey data on expectations about the future state of the economy:

First Step. Using the Fisher equation given in Table 1, I re-express the Phillips curve, the dynamic IS equation, and the monetary policy rule for the Home country as follows:

$$
\begin{aligned}
\widehat{\pi}_{t} & \approx \beta \mathbb{E}_{t}\left(\widehat{\pi}_{t+1}\right)+\Phi(\varphi+\gamma)\left[\kappa \widehat{x}_{t}+(1-\kappa) \widehat{x}_{t}^{*}+(1-\xi) \widehat{u}_{t}+\xi \widehat{u}_{t}^{*}\right] \\
\gamma\left(\mathbb{E}_{t}\left(\widehat{x}_{t+1}\right)-\widehat{x}_{t}\right) & \approx-\Omega \widehat{r}_{t}^{\text {gap }}-(1-\Omega) \widehat{r}_{t}^{* g a p} \\
-\widehat{r}_{t}^{g a p} & \approx \psi_{\pi} \widehat{\pi}_{t}+\psi_{x} \widehat{x}_{t}+\widehat{m}_{t}
\end{aligned}
$$

and, similarly, for the Foreign country as:

$$
\begin{aligned}
\widehat{\pi}_{t}^{*} & \approx \beta \mathbb{E}_{t}\left(\widehat{\pi}_{t+1}^{*}\right)+\Phi(\varphi+\gamma)\left[(1-\kappa) \widehat{x}_{t}+\kappa \widehat{x}_{t}^{*}+\xi \widehat{u}_{t}+(1-\xi) \widehat{u}_{t}^{*}\right] \\
\gamma\left(\mathbb{E}_{t}\left(\widehat{x}_{t+1}^{*}\right)-\widehat{x}_{t}^{*}\right) & \approx-(1-\Omega) \widehat{r}_{t}^{g a p}-\Omega \widehat{r}_{t}^{* g a p} \\
-\widehat{r}_{t}^{* g a p} & \approx \psi_{\pi} \widehat{\pi}_{t}^{*}+\psi_{x} \widehat{x}_{t}^{*}+\widehat{m}_{t}^{*}
\end{aligned}
$$

where I define the deviations of the natural rate from its corresponding real interest rate in the Home and Foreign country as $\widehat{r}_{t}^{g a p} \equiv\left(\widehat{\bar{r}}_{t}-\widehat{r}_{t}\right)$ and $\widehat{r}_{t}^{* g a p} \equiv\left(\widehat{\bar{r}}_{t}^{*}-\widehat{r}_{t}^{*}\right)$, respectively. Given equations (58) - (63), I can express the vector of endogenous variables $\widehat{Y}_{t}$ to be $\widehat{Y}_{t}=\left(\widehat{\pi}_{t}, \widehat{\pi}_{t}^{*}, \widehat{x}_{t}, \widehat{x}_{t}^{*}, \widehat{r}_{t}^{g a p}, \widehat{r}_{t}^{* g a p}\right)^{T}$. Equations (58)-(63) are the counterpart of the general-form representation in (44). The shock processes in Table 2 together with the equations for the natural rate and output potential in Table 1 describe the model's particular representation of the general-form in equation (45). Therefore, the exogenous shock processes and their corresponding shock innovations can be expressed as $\widehat{X}_{t}=\left(\widehat{\bar{r}}_{t}, \widehat{\bar{r}}_{t}^{*}, \widehat{\bar{y}}_{t}, \widehat{\bar{y}}_{t}^{*}, \widehat{a}_{t}, \widehat{a}_{t}^{*}, \widehat{u}_{t}, \widehat{u}_{t}^{*}, \widehat{m}_{t}, \widehat{m}_{t}^{*}\right)$ and $\widehat{\varepsilon}_{t}=\left(\widehat{\varepsilon}_{t}^{a}, \widehat{\varepsilon}_{t}^{a *}, \widehat{\varepsilon}_{t}^{u}, \widehat{\varepsilon}_{t}^{u *}, \widehat{\varepsilon}_{t}^{m}, \widehat{\varepsilon}_{t}^{m *}\right)$, respectively.

Output gap and the real interest rate gap are expressed in deviations from their frictionless counterparts, and inflation is expressed in deviations from the zero-inflation target (which is the deterministic steady state). Hence, if the trends present in the data for inflation, for output, and for the real rate are unaffected by the presence or lack thereof of nominal rigidities, none of the variables in $\widehat{Y}_{t}$ ought to be affected by those trends as they cancel out given that all variables in $\widehat{Y}_{t}$ are constructed in deviations. Accordingly, what equations $(58)-(63)$ and the vector $\widehat{Y}_{t}=\left(\widehat{\pi}_{t}, \widehat{\pi}_{t}^{*}, \widehat{x}_{t}, \widehat{x}_{t}^{*}, \widehat{r}_{t}^{\text {gap }}, \widehat{r}_{t}^{* \text { gap }}\right)^{T}$ describe is a system of 3 equations and 3 unknown variables per country which is stationary and unaffected by data trends. This is consistent with the theory since, after all, the model posited here is agnostic about trends. Trends which do appear in the data are taken into account via the observation equations and therefore outside the model, as I discuss later in more detail. 
Second Step. The characterization of the "cost-push" shocks, $\widehat{u}_{t}$ and $\widehat{u}_{t}^{*}$, and the monetary policy shocks, $\widehat{m}_{t}$ and $\widehat{m}_{t}^{*}$, follows directly from the processes in Table 2 . The productivity shocks, $\widehat{a}_{t}$ and $\widehat{a}_{t}^{*}$, reported in Table 2 do not directly affect the workhorse model but instead feed through the potential allocation. The following linear mappings derived earlier describe the relationship for the Home country:

$\widehat{\bar{r}}_{t} \approx \gamma\left(\frac{1+\varphi}{\gamma+\varphi}\right)\left[\begin{array}{c}\left((\Theta \Lambda+(1-\Theta)(1-\Lambda))\left(\delta_{a}-1\right)+(1-(\Theta \Lambda+(1-\Theta)(1-\Lambda))) \delta_{a, a^{*}}\right) \widehat{a}_{t}+\ldots . . \\ \left((\Theta \Lambda+(1-\Theta)(1-\Lambda)) \delta_{a, a^{*}}+(1-(\Theta \Lambda+(1-\Theta)(1-\Lambda)))\left(\delta_{a}-1\right)\right) \widehat{a}_{t}^{*}\end{array}\right]$
$\widehat{\bar{y}}_{t} \approx\left(\frac{1+\varphi}{\gamma+\varphi}\right)\left[\Lambda \widehat{a}_{t}+(1-\Lambda) \widehat{a}_{t}^{*}\right]$,

as well as for the Foreign country:

$\widehat{\bar{r}}_{t}^{*} \approx \gamma\left(\frac{1+\varphi}{\gamma+\varphi}\right)\left[\begin{array}{c}\left((\Theta \Lambda+(1-\Theta)(1-\Lambda)) \delta_{a, a^{*}}+(1-(\Theta \Lambda+(1-\Theta)(1-\Lambda)))\left(\delta_{a}-1\right)\right) \widehat{a}_{t}+\ldots \\ \left((\Theta \Lambda+(1-\Theta)(1-\Lambda))\left(\delta_{a}-1\right)+(1-(\Theta \Lambda+(1-\Theta)(1-\Lambda))) \delta_{a, a^{*}}\right) \widehat{a}_{t}^{*}\end{array}\right]$

$\widehat{\bar{y}}_{t}^{*} \approx\left(\frac{1+\varphi}{\gamma+\varphi}\right)\left[(1-\Lambda) \widehat{a}_{t}+\Lambda \widehat{a}_{t}^{*}\right]$,

in terms of the Home and Foreign productivity levels, $\widehat{a}_{t}$ and $\widehat{a}_{t}^{*}$. I can re-write the natural rates in both countries more compactly as:

$$
\begin{aligned}
& \left.\widehat{\bar{r}}_{t} \approx \gamma\left(\frac{1+\varphi}{\gamma+\varphi}\right)\left[\left(\delta_{a, a^{*}}+\Theta^{\Lambda}\left(\delta_{a}-\delta_{a, a^{*}}-1\right)\right) \widehat{a}_{t}+\left(\left(\delta_{a}-1\right)-\Theta^{\Lambda}\left(\delta_{a}-\delta_{a, a^{*}}-1\right)\right) \widehat{a}_{t}^{*}\right] 68\right) \\
& \widehat{\bar{r}}_{t}^{*} \approx \gamma\left(\frac{1+\varphi}{\gamma+\varphi}\right)\left[\left(\left(\delta_{a}-1\right)-\Theta^{\Lambda}\left(\delta_{a}-\delta_{a, a^{*}}-1\right)\right) \widehat{a}_{t}+\left(\delta_{a, a^{*}}+\Theta^{\Lambda}\left(\delta_{a}-\delta_{a, a^{*}}-1\right)\right) \widehat{a}_{t}^{*}\right][69)
\end{aligned}
$$

where I define the composite coefficient $\Theta^{\Lambda}$ to be $\Theta^{\Lambda} \equiv(\Theta \Lambda+(1-\Theta)(1-\Lambda))$. Hence, given this, the general-form equation (46) for this model must include equations (64) - (67) together with the shock processes for productivity shocks, "cost-push" shocks, and monetary policy shocks already described in Table 2 .

Except for Home and Foreign inflation, $\widehat{\pi}_{t}$ and $\widehat{\pi}_{t}^{*}$, the other variables in the vector $\widehat{Y}_{t}$ are not observable because they depend on the unobservable output potential and the unobservable natural rate of interest. Hence, a number of additional equations have to be included to map these unobservable endogenous variables to observable endogenous ones for the estimation. In particular, I use the production function and the output definition in Table 1 to relate the output gap of the Home and Foreign country, $\widehat{x}_{t}$ and $\widehat{x}_{t}^{*}$, to the corresponding labor productivity measures, $\widehat{y}_{t}-\widehat{l}_{t}$ and $\widehat{y}_{t}^{*}-\widehat{l}_{t}^{*}$ respectively, where $\widehat{l}_{t}$ denotes 
Home labor and $\widehat{l_{t}^{*}}$ Foreign labor. To do this, I use the output definition to recover Home and Foreign output, $\widehat{y}_{t}$ and $\widehat{y}_{t}^{*}$, as follows:

$$
\begin{aligned}
\widehat{y}_{t} & \equiv \widehat{\bar{y}}_{t}+\widehat{x}_{t} \\
\widehat{y}_{t}^{*} & \equiv \widehat{\bar{y}}_{t}^{*}+\widehat{x}_{t}^{*}
\end{aligned}
$$

Then, given the linear-in-labor production technology assumed in the model, labor productivity is simply expressed as:

$$
\begin{aligned}
\widehat{y}_{t}-\widehat{l}_{t} & \approx \widehat{a}_{t}, \\
\widehat{y}_{t}^{*}-\widehat{l}_{t}^{*} & \approx \widehat{a}_{t}^{*} .
\end{aligned}
$$

Equations (70) - (71) and (72) - (73) are included in the general-form equation (46). Equations $(72)$ - (73) are particularly important because labor productivity is observable and equates with the model's productivity shocks. Hence, that means in effect that Home and Foreign productivity, $\widehat{a}_{t}$ and $\widehat{a}_{t}^{*}$, can be identified using Home and Foreign labor productivity, $\widehat{y}_{t}-\widehat{l}_{t}$ and $\widehat{y}_{t}^{*}-\widehat{l}_{t}^{*}$, as observables. Using labor productivity as an observable instead of simply using output has also the added advantage that it implicitly controls for population growth as well, something on which the model itself is clearly silent.

Furthermore, the Fisher equations given in Table 1 define the Home and Foreign real rates of interest, $\widehat{r}_{t}$ and $\widehat{r}_{t}^{*}$, as:

$$
\begin{aligned}
& \widehat{r}_{t} \approx \widehat{i}_{t}-\mathbb{E}_{t}\left(\widehat{\pi}_{t+1}\right), \\
& \widehat{r}_{t}^{*} \approx \widehat{i}_{t}^{*}-\mathbb{E}_{t}\left(\widehat{\pi}_{t+1}^{*}\right),
\end{aligned}
$$

It follows from the definition of the Home and Foreign natural (real) interest rate gap, $\widehat{r}_{t}^{g a p}$ and $\widehat{r}_{t}^{* g a p}$, that the Home and Foreign natural rates of interest, $\widehat{r}_{t}$ and $\widehat{r}_{t}^{*}$, can be written as follows:

$$
\begin{aligned}
\widehat{r}_{t} & \equiv \widehat{\bar{r}}_{t}-\widehat{r}_{t}^{g a p} \\
\widehat{r}_{t}^{*} & \equiv \widehat{\bar{r}}_{t}^{*}-\widehat{r}_{t}^{* g a p} .
\end{aligned}
$$

Given equations $(74)$ - (75) and (76) - (77), the Home and Foreign short-term nominal 
interest rates, $\widehat{i}_{t}$ and $\widehat{i}_{t}^{*}$, can be re-expressed in the following terms:

$$
\begin{aligned}
\widehat{i}_{t} & \approx \widehat{\bar{r}}_{t}-\widehat{r}_{t}^{g a p}+\mathbb{E}_{t}\left(\widehat{\pi}_{t+1}\right), \\
\widehat{i}_{t}^{*} & \approx \widehat{\bar{r}}_{t}^{*}-\widehat{r}_{t}^{* g a p}+\mathbb{E}_{t}\left(\widehat{\pi}_{t+1}^{*}\right),
\end{aligned}
$$

where equations $(74)-(75),(76)$, and (79) are also added to the general-form in equation (46).

An implication of equations (78) - (79) is that the Home and Foreign natural rates of interest can be also described as:

$$
\begin{aligned}
& \widehat{\bar{r}}_{t} \approx \widehat{i}_{t}-\mathbb{E}_{t}\left(\widehat{\pi}_{t+1}\right)+\widehat{r}_{t}^{g a p}, \\
& \widehat{\bar{r}}_{t}^{*} \approx \widehat{i}_{t}^{*}-\mathbb{E}_{t}\left(\widehat{\pi}_{t+1}^{*}\right)+\widehat{r}_{t}^{* g a p},
\end{aligned}
$$

which means that the natural rate of interest equals the Home and Foreign real rate of interest, $\widehat{r}_{t} \approx \widehat{i}_{t}-\mathbb{E}_{t}\left(\widehat{\pi}_{t+1}\right)$ and $\widehat{r}_{t}^{*} \approx \widehat{i}_{t}^{*}-\mathbb{E}_{t}\left(\widehat{\pi}_{t+1}^{*}\right)$, plus the stationary fluctuations of the corresponding Home and Foreign real rate gaps, $\widehat{r}_{t}^{\text {gap }}$ and $\widehat{r}_{t}^{* g a p}$, determined by the equilibrium conditions of the model (i.e., by the set of equations in (58) - (63) which pins down $\widehat{Y}_{t}=$ $\left.\left(\widehat{\pi}_{t}, \widehat{\pi}_{t}^{*}, \widehat{x}_{t}, \widehat{x}_{t}^{*}, \widehat{r}_{t}^{g a p}, \widehat{r}_{t}^{* g a p}\right)^{T}\right)$. Hence, if I observe the Home real rate $\widehat{r}_{t} \approx \widehat{i}_{t}-\mathbb{E}_{t}\left(\widehat{\pi}_{t+1}\right)$, then I can infer the Home natural rate of interest simply by adding the estimated Home natural rate gap $\widehat{r}_{t}^{g a p}$ recovered with the estimated model.

Finally, equations (74) - (75), (76), and (79) provide another pair of observable variables: the Home short-term real interest rate and the Foreign short-term nominal interest rate, $\widehat{r}_{t}$ and $\widehat{i}_{t}^{*}$. Here I am already taking advantage of the fact that I observe survey data on the Home country inflation expectations, $\mathbb{E}_{t}\left(\widehat{\pi}_{t+1}\right)$, and I also observe the Home short-term nominal interest rate, $\widehat{i}_{t}$, so I can construct the Home real rate implied by the Fisher equation in (74), $\widehat{r}_{t}$, to be used as one of my observables. Accordingly, the vector of other endogenous variables $\widehat{Y}_{t}^{o}$ is given by $\widehat{Y}_{t}^{o}=\left(\widehat{\bar{r}}_{t}, \widehat{\bar{r}}_{t}^{*}, \widehat{\bar{y}}_{t}, \widehat{\bar{y}}_{t}^{*}, \widehat{y}_{t}, \widehat{y}_{t}^{*}, \widehat{y}_{t}-\widehat{l}_{t}, \widehat{y}_{t}^{*}-\widehat{l}_{t}^{*}, \widehat{r}_{t}, \widehat{r}_{t}^{*}, \widehat{i}_{t}, \widehat{i}_{t}^{*}\right)^{T}$ and the vector of observables for the model (not including expectations) is $\widehat{Y}_{t}^{o b s}=\left(\widehat{\pi}_{t}, \widehat{\pi}_{t}^{*}, \widehat{y}_{t}-\widehat{l}_{t}, \widehat{y}_{t}^{*}-\widehat{l}_{t}^{*}, \widehat{r}_{t}, \widehat{i}_{t}^{*}\right)^{T} \subseteq$ $\left\{\widehat{Y}_{t}, \widehat{Y}_{t}^{o}\right\}$ or, alternatively, $\widehat{Y}_{t}^{o b s}=\left(\widehat{\pi}_{t}, \widehat{\pi}_{t}^{*}, \widehat{a}_{t}, \widehat{a}_{t}^{*}, \widehat{r}_{t}, \widehat{i}_{t}^{*}\right)^{T} \subseteq\left\{\widehat{Y}_{t}, \widehat{Y}_{t}^{o}, \widehat{X}_{t}\right\}$. 
Third Step. I can re-write the system of equations in (58) - (63) replacing out the definitions $\widehat{r}_{t}^{\text {gap }} \equiv\left(\widehat{\bar{r}}_{t}-\widehat{r}_{t}\right)$ and $\widehat{r}_{t}^{* g a p} \equiv\left(\widehat{\bar{r}}_{t}^{*}-\widehat{r}_{t}^{*}\right)$ as follows:

$$
\begin{aligned}
\widehat{\pi}_{t} & \approx \beta \mathbb{E}_{t}\left(\widehat{\pi}_{t+1}\right)+\Phi(\varphi+\gamma)\left[\kappa \widehat{x}_{t}+(1-\kappa) \widehat{x}_{t}^{*}+(1-\xi) \widehat{u}_{t}+\xi \widehat{u}_{t}^{*}\right] \\
\gamma\left(\mathbb{E}_{t}\left(\widehat{x}_{t+1}\right)-\widehat{x}_{t}\right) & \approx \Omega\left(\widehat{r}_{t}-\widehat{\bar{r}}_{t}\right)+(1-\Omega)\left(\widehat{r}_{t}^{*}-\widehat{\bar{r}}_{t}^{*}\right) \\
\widehat{r}_{t} & \approx \widehat{\bar{r}}_{t}+\psi_{\pi} \widehat{\pi}_{t}+\psi_{x} \widehat{x}_{t}+\widehat{m}_{t} \\
\widehat{\pi}_{t}^{*} & \approx \beta \mathbb{E}_{t}\left(\widehat{\pi}_{t+1}^{*}\right)+\Phi(\varphi+\gamma)\left[(1-\kappa) \widehat{x}_{t}+\kappa \widehat{x}_{t}^{*}+\xi \widehat{u}_{t}+(1-\xi) \widehat{u}_{t}^{*}\right], \\
\gamma\left(\mathbb{E}_{t}\left(\widehat{x}_{t+1}^{*}\right)-\widehat{x}_{t}^{*}\right) & \approx(1-\Omega)\left(\widehat{r}_{t}-\widehat{\bar{r}}_{t}\right)+\Omega\left(\widehat{r}_{t}^{*}-\widehat{\bar{r}}_{t}^{*}\right) \\
\widehat{r}_{t}^{*} & \approx \widehat{\bar{r}}_{t}^{*}+\psi_{\pi} \widehat{\pi}_{t}^{*}+\psi_{x} \widehat{x}_{t}^{*}+\widehat{m}_{t}^{*} .
\end{aligned}
$$

Moreover, the Home and Foreign natural rates, $\widehat{\bar{r}}_{t}$ and $\widehat{\widehat{r}}_{t}^{*}$, are a linear mapping of the Home and Foreign productivity shocks, $\widehat{a}_{t}$ and $\widehat{a}_{t}^{*}$, as shown in equations (68) - (69). Given this, it is possible to write the system of equilibrium conditions for inflation and the output gap in matrix form as follows:

$$
\begin{aligned}
& \left(\begin{array}{cccc}
1 & 0 & -\Phi(\varphi+\gamma) \kappa & -\Phi(\varphi+\gamma)(1-\kappa) \\
0 & 1 & -\Phi(\varphi+\gamma)(1-\kappa) & -\Phi(\varphi+\gamma) \kappa \\
0 & 0 & 1 & 0 \\
0 & 0 & 0 & 1
\end{array}\right)\left(\begin{array}{c}
\widehat{\pi}_{t} \\
\widehat{\pi}_{t}^{*} \\
\widehat{x}_{t} \\
\widehat{x}_{t}^{*}
\end{array}\right)=\left(\begin{array}{cccc}
\beta & 0 & 0 & 0 \\
0 & \beta & 0 & 0 \\
0 & 0 & 1 & 0 \\
0 & 0 & 0 & 1
\end{array}\right)\left(\begin{array}{c}
\mathbb{E}_{t}\left(\widehat{\pi}_{t+1}\right) \\
\mathbb{E}_{t}\left(\widehat{\pi}_{t+1}^{*}\right) \\
\mathbb{E}_{t}\left(\widehat{x}_{t+1}\right) \\
\mathbb{E}_{t}\left(\widehat{x}_{t+1}^{*}\right)
\end{array}\right)+\ldots
\end{aligned}
$$

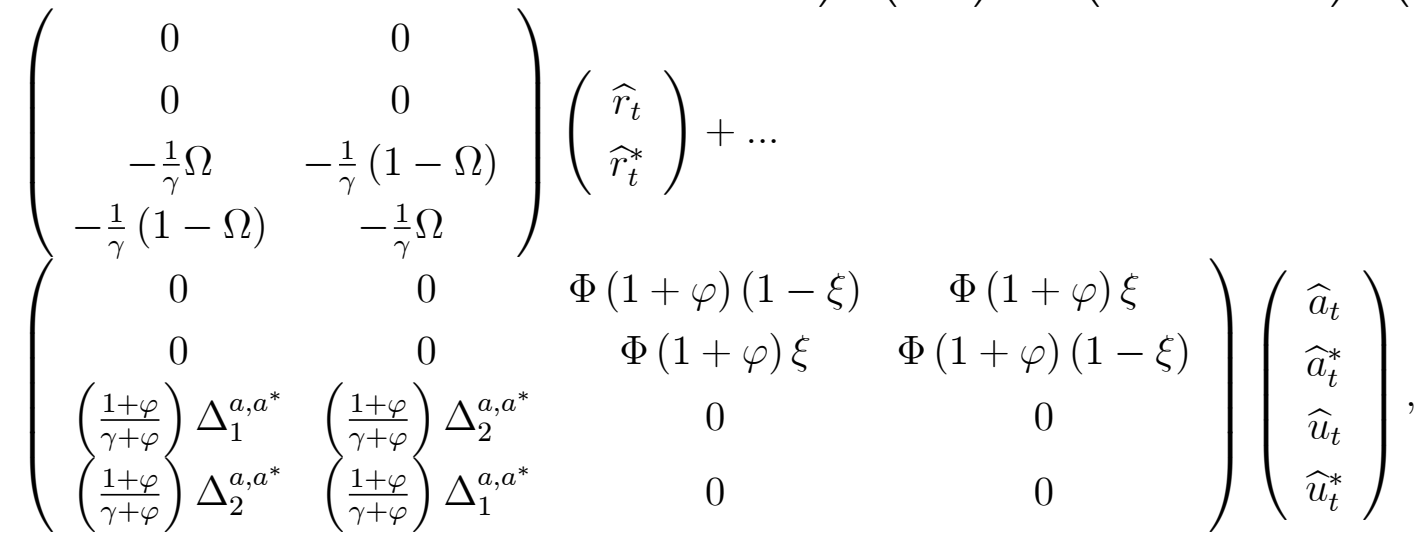

where I define the composite coefficients $\Delta_{1}^{a, a^{*}} \equiv \delta_{a, a^{*}}+\left((1-\Omega)\left(1-\Theta^{\Lambda}\right)+\Omega \Theta^{\Lambda}\right)\left(\delta_{a}-\delta_{a, a^{*}}-1\right)$ and $\Delta_{2}^{a, a^{*}} \equiv\left(\delta_{a}-1\right)-\left((1-\Omega)\left(1-\Theta^{\Lambda}\right)+\Omega \Theta^{\Lambda}\right)\left(\delta_{a}-\delta_{a, a^{*}}-1\right)$. More compactly, I can 
express this system of equations as:

$$
\begin{aligned}
& \left(\begin{array}{c}
\widehat{\pi}_{t} \\
\widehat{\pi}_{t}^{*} \\
\widehat{x}_{t} \\
\widehat{x}_{t}^{*}
\end{array}\right)=\left(\begin{array}{cccc}
\beta & 0 & \Phi(\varphi+\gamma) \kappa & \Phi(\varphi+\gamma)(1-\kappa) \\
0 & \beta & \Phi(\varphi+\gamma)(1-\kappa) & \Phi(\varphi+\gamma) \kappa \\
0 & 0 & 1 & 0 \\
0 & 0 & 0 & 1
\end{array}\right)\left(\begin{array}{c}
\mathbb{E}_{t}\left(\widehat{\pi}_{t+1}\right) \\
\mathbb{E}_{t}\left(\widehat{\pi}_{t+1}^{*}\right) \\
\mathbb{E}_{t}\left(\widehat{x}_{t+1}\right) \\
\mathbb{E}_{t}\left(\widehat{x}_{t+1}^{*}\right)
\end{array}\right)+\ldots \\
& \left(\begin{array}{cc}
-\Phi(\varphi+\gamma) \frac{1}{\gamma}[\kappa \Omega+(1-\kappa)(1-\Omega)] & -\Phi(\varphi+\gamma) \frac{1}{\gamma}[\kappa(1-\Omega)+(1-\kappa) \Omega] \\
-\Phi(\varphi+\gamma) \frac{1}{\gamma}[\kappa(1-\Omega)+(1-\kappa) \Omega] & -\Phi(\varphi+\gamma) \frac{1}{\gamma}[\kappa \Omega+(1-\kappa)(1-\Omega)] \\
-\frac{\Omega}{\gamma} & -\frac{1}{\gamma}(1-\Omega) \\
-\frac{1}{\gamma}(1-\Omega) & -\frac{\Omega}{\gamma}
\end{array}\right)\left(\begin{array}{c}
\widehat{r}_{t} \\
\widehat{r}_{t}^{*}
\end{array}\right)+\ldots \\
& \left(\begin{array}{cccc}
\Phi(1+\varphi) \Delta_{1}^{\kappa} & \Phi(1+\varphi) \Delta_{2}^{\kappa} & \Phi(1+\varphi)(1-\xi) & \Phi(1+\varphi) \xi \\
\Phi(1+\varphi) \Delta_{2}^{\kappa} & \Phi(1+\varphi) \Delta_{1}^{\kappa} & \Phi(1+\varphi) \xi & \Phi(1+\varphi)(1-\xi) \\
\left(\frac{1+\varphi}{\gamma+\varphi}\right) \Delta_{1}^{a, a^{*}} & \left(\frac{1+\varphi}{\gamma+\varphi}\right) \Delta_{2}^{a, a^{*}} & 0 & 0 \\
\left(\frac{1+\varphi}{\gamma+\varphi}\right) \Delta_{2}^{a, a^{*}} & \left(\frac{1+\varphi}{\gamma+\varphi}\right) \Delta_{1}^{a, a^{*}} & 0 & 0
\end{array}\right)\left(\begin{array}{c}
\widehat{a}_{t} \\
\widehat{a}_{t}^{*} \\
\widehat{u}_{t} \\
\widehat{u}_{t}^{*}
\end{array}\right),
\end{aligned}
$$

with $\Delta_{1}^{\kappa} \equiv\left[\kappa \Delta_{1}^{a, a^{*}}+(1-\kappa) \Delta_{2}^{a, a^{*}}\right]$ and $\Delta_{2}^{\kappa} \equiv\left[(1-\kappa) \Delta_{1}^{a, a^{*}}+\kappa \Delta_{2}^{a, a^{*}}\right]$; or, simply as:

$$
\left(\begin{array}{c}
\widehat{\pi}_{t} \\
\widehat{\pi}_{t}^{*} \\
\widehat{x}_{t} \\
\widehat{x}_{t}^{*}
\end{array}\right)=\Phi_{1}(\lambda)\left(\begin{array}{c}
\mathbb{E}_{t}\left(\widehat{\pi}_{t+1}\right) \\
\mathbb{E}_{t}\left(\widehat{\pi}_{t+1}^{*}\right) \\
\mathbb{E}_{t}\left(\widehat{x}_{t+1}\right) \\
\mathbb{E}_{t}\left(\widehat{x}_{t+1}^{*}\right)
\end{array}\right)+\Phi_{2}(\lambda)\left(\begin{array}{c}
\widehat{r}_{t} \\
\widehat{r}_{t}^{*}
\end{array}\right)+\Phi_{3}(\lambda)\left(\begin{array}{c}
\widehat{a}_{t} \\
\widehat{a}_{t}^{*} \\
\widehat{u}_{t} \\
\widehat{u}_{t}^{*}
\end{array}\right)
$$

where I collect the 18 structural parameters of the model as well as the parameters of the shock processes in the following vector:

$$
\lambda=\left(\beta, \gamma, \varphi, \sigma, \xi, \alpha, \psi_{\pi}, \psi_{x} ; \delta_{a}, \delta_{a, a^{*}}, \sigma_{a}, \rho_{a, a^{*}}, \delta_{u}, \sigma_{u}, \rho_{u, u^{*}}, \delta_{m}, \sigma_{m}, \rho_{m, m^{*}}\right)^{T}
$$

This particular way of representing the system of equilibrium conditions can be further re-arranged replacing out the output gap with the output definitions in (70) - (71) such that:

$$
\left(\begin{array}{c}
\widehat{\pi}_{t} \\
\widehat{\pi}_{t}^{*} \\
\widehat{y}_{t} \\
\widehat{y}_{t}^{*}
\end{array}\right)=\Phi_{1}(\lambda)\left(\begin{array}{c}
\mathbb{E}_{t}\left(\widehat{\pi}_{t+1}\right) \\
\mathbb{E}_{t}\left(\widehat{\pi}_{t+1}^{*}\right) \\
\mathbb{E}_{t}\left(\widehat{x}_{t+1}\right) \\
\mathbb{E}_{t}\left(\widehat{x}_{t+1}^{*}\right)
\end{array}\right)+\Phi_{2}(\lambda)\left(\begin{array}{c}
\widehat{r}_{t} \\
\widehat{r}_{t}^{*}
\end{array}\right)+\widetilde{\Phi}_{3}(\lambda)\left(\begin{array}{c}
\widehat{a}_{t} \\
\widehat{a}_{t}^{*} \\
\widehat{u}_{t} \\
\widehat{u}_{t}^{*}
\end{array}\right),
$$


where $\widetilde{\Phi}_{3}(\lambda)$ is defined as:

$$
\left(\begin{array}{cccc}
\Phi(1+\varphi) \Delta_{1}^{\kappa} & \Phi(1+\varphi) \Delta_{2}^{\kappa} & \Phi(1+\varphi)(1-\xi) & \Phi(1+\varphi) \xi \\
\Phi(1+\varphi) \Delta_{2}^{\kappa} & \Phi(1+\varphi) \Delta_{1}^{\kappa} & \Phi(1+\varphi) \xi & \Phi(1+\varphi)(1-\xi) \\
\left(\frac{1+\varphi}{\gamma+\varphi}\right)\left[\Lambda+\Delta_{1}^{a, a^{*}}\right] & \left(\frac{1+\varphi}{\gamma+\varphi}\right)\left[(1-\Lambda)+\Delta_{2}^{a, a^{*}}\right] & 0 & 0 \\
\left(\frac{1+\varphi}{\gamma+\varphi}\right)\left[(1-\Lambda)+\Delta_{2}^{a, a^{*}}\right] & \left(\frac{1+\varphi}{\gamma+\varphi}\right)\left[\Lambda+\Delta_{1}^{a, a^{*}}\right] & 0 & 0
\end{array}\right)
$$

using the formulas for the Home and Foreign output potential in (65) and (67).

The reason why I re-write the system of equations for inflation and output as in (91) is because, ruling out bubbles, the path of both variables in the Home and Foreign countries now can be expressed in present-value terms. To show that, let me first define the matrix $A_{1}$ as:

$$
A_{1} \equiv\left(\begin{array}{cccc}
\delta_{a} & \delta_{a, a^{*}} & 0 & 0 \\
\delta_{a, a^{*}} & \delta_{a} & 0 & 0 \\
0 & 0 & \delta_{u} & 0 \\
0 & 0 & 0 & \delta_{u}
\end{array}\right)
$$

Then, the present-value form of the model can be written as:

$$
\begin{gathered}
\left(\begin{array}{c}
\widehat{\pi}_{t} \\
\widehat{\pi}_{t}^{*} \\
\widehat{y}_{t} \\
\widehat{y}_{t}^{*}
\end{array}\right)=\Phi_{2}(\lambda)\left(\begin{array}{c}
\widehat{i}_{t} \\
\hat{i}_{t}^{*}
\end{array}\right)+\sum_{\tau=1}^{T} \Phi_{1}(\lambda)^{\tau} \Phi_{2}(\lambda)\left(\begin{array}{c}
\mathbb{E}_{t}\left(\widehat{r}_{t+\tau}\right) \\
\mathbb{E}_{t}\left(\widehat{r}_{t+\tau}^{*}\right)
\end{array}\right)+\ldots \\
{\left[\sum_{\tau=0}^{T} \Phi_{1}(\lambda)^{\tau} \Phi_{2}(\lambda) A_{1}^{\tau}\right]\left(\begin{array}{c}
\widehat{a}_{t} \\
\widehat{a}_{t}^{*} \\
\widehat{u}_{t} \\
\widehat{u}_{t}^{*}
\end{array}\right)+\Phi_{1}(\lambda)^{T+1}\left(\begin{array}{c}
\mathbb{E}_{t}\left(\widehat{\pi}_{t+T+1}\right) \\
\mathbb{E}_{t}\left(\widehat{\pi}_{t+T+1}^{*}\right) \\
\mathbb{E}_{t}\left(\widehat{x}_{t+T+1}\right) \\
\mathbb{E}_{t}\left(\widehat{x}_{t+T+1}^{*}\right)
\end{array}\right) .}
\end{gathered}
$$

After a straightforward eigendecomposition of $\Phi_{1}(\lambda)$, I can write $\Phi_{1}(\lambda)^{T+1}$ as $\Phi_{1}(\lambda)^{T+1}=$ $Q(\lambda) \Sigma(\lambda)^{T+1} Q(\lambda)^{-1}$ where $Q(\lambda)$ is the corresponding matrix of the eigenvectors and $\Sigma(\lambda) \equiv\left(\begin{array}{cccc}\beta & 0 & 0 & 0 \\ 0 & \beta & 0 & 0 \\ 0 & 0 & 1 & 0 \\ 0 & 0 & 0 & 1\end{array}\right)$ is the diagonal matrix whose diagonal elements are the correspond- 
ing eigenvalues of $\Phi_{1}(\lambda)$. Ruling out bubbles implies that $\lim _{T \rightarrow+\infty} \Phi_{1}(\lambda)^{T+1}\left(\begin{array}{l}\mathbb{E}_{t}\left(\widehat{\pi}_{t+T+1}\right) \\ \mathbb{E}_{t}\left(\widehat{\pi}_{t+T+1}^{*}\right) \\ \mathbb{E}_{t}\left(\widehat{x}_{t+T+1}\right) \\ \mathbb{E}_{t}\left(\widehat{x}_{t+T+1}^{*}\right)\end{array}\right)=$ 0 which holds if the eigenvalues in $\Sigma(\lambda)$ are all strictly inside the unit circle or, in this case, if $\lim _{T \rightarrow+\infty}=\mathbb{E}_{t}\left(\widehat{x}_{t+T+1}\right)=\mathbb{E}_{t}\left(\widehat{x}_{t+T+1}^{*}\right)=0$. If that is the case, it follows from (94) that the dynamics of the Home and Foreign economy given by output and inflation can be related to the contemporaneous realization of the vector of productivity and "cost-push" shocks $\left(\widehat{a}_{t}, \widehat{a}_{t}^{*}, \widehat{u}_{t}, \widehat{u}_{t}^{*}\right)^{T}$ as well as to the path of current real interest rates, $\widehat{r}_{t}$ and $\widehat{r}_{t}^{*}$, and expected future real interest rates, $\mathbb{E}_{t}\left(\widehat{r}_{t+\tau}\right)$ and $\mathbb{E}_{t}\left(\widehat{r}_{t+\tau}^{*}\right)$ for all $\tau>0$, i.e.,

$$
\left(\begin{array}{c}
\widehat{\pi}_{t} \\
\widehat{\pi}_{t}^{*} \\
\widehat{y}_{t} \\
\widehat{y}_{t}^{*}
\end{array}\right)=\Phi_{2}(\lambda)\left(\begin{array}{c}
\widehat{r}_{t} \\
\widehat{r}_{t}^{*}
\end{array}\right)+\sum_{\tau=1}^{+\infty} \Phi_{1}(\lambda)^{\tau} \Phi_{2}(\lambda)\left(\begin{array}{c}
\mathbb{E}_{t}\left(\widehat{r}_{t+\tau}\right) \\
\mathbb{E}_{t}\left(\widehat{r}_{t+\tau}^{*}\right)
\end{array}\right)+\left[\sum_{\tau=0}^{+\infty} \Phi_{1}(\lambda)^{\tau} \Phi_{2}(\lambda) A_{1}^{\tau}\right]\left(\begin{array}{c}
\widehat{a}_{t} \\
\widehat{a}_{t}^{*} \\
\widehat{u}_{t} \\
\widehat{u}_{t}^{*}
\end{array}\right)
$$

It is this relationship in (95) what allows me to argue that to ensure consistency with the zero-lower bound constraint, I must have in my observation set data about not just current real interest rates $\left\{\widehat{r}_{t}, \widehat{r}_{t}^{*}\right\}$ but also about the expected path of the future real interest rates $\left\{\mathbb{E}_{t}\left(\widehat{r}_{t+\tau}\right), \mathbb{E}_{t}\left(\widehat{r}_{t+\tau}^{*}\right)\right\}$ to discipline the solution. In other words, the relationship in (95) suggests that I do not require expectations about future inflation and output per se if I have expectations about the future real interest rate with which to discipline the solution of the model to make it consistent with the implications of the zero-lower bound constraint.

In my estimation, I include all horizons of the interest rate for which there is survey data available for the U.S., i.e., I include all observations on the empirical counterparts of $\left\{\widehat{r}_{t}, \mathbb{E}_{t}\left(\widehat{r}_{t+\tau}\right)\right\}$ that are readily available. Equation (91) and, accordingly, equation (95) can be re-written so as to replace out the Foreign real interest rate with the Foreign nominal interest rate using the Fisher equation in (75). That would be more in keeping with the reality that only the Foreign country nominal short-term interest rates are in practice observable. Even so, the expectations of the future path of neither the nominal nor the real Foreign interest rate are available. So, in effect, those expectations are unconstrained by the data. However, as I argued before, the impact on the solution is thought to be negligible because the solution unconstrained by the zero-lower bound in the Foreign country is likely very close to the solution constrained by the zero-lower bound constraint given that short-term nominal interest rates are far from zero during the sample period used in the estimation. 
Fourth Step. I map the endogenous expectations to survey data. As indicated before, the model given in Table 1 involves only expectations for four of the six endogenous variables in the vector $\widehat{Y}_{t}=\left(\widehat{\pi}_{t}, \widehat{\pi}_{t}^{*}, \widehat{x}_{t}, \widehat{x}_{t}^{*}, \widehat{r}_{t}^{g a p}, \widehat{r}_{t}^{* g a p}\right)^{T}$; to be precise, it involves forming expectations on future inflation and the output gap (or output) of each country. However, as shown in (95), the expectations for the real interest rate in the Home and Foreign country for each horizon $h>0$ as given by the vector $\left(\mathbb{E}_{t}\left(\widehat{r}_{t+1}\right), \ldots, \mathbb{E}_{t}\left(\widehat{r}_{t+h}\right), \mathbb{E}_{t}\left(\widehat{r}_{t+1}^{*}\right), \ldots, \mathbb{E}_{t}\left(\widehat{r}_{t+h}^{*}\right)\right)$ is all that one actually would need to shape the path of inflation and the output gap (output) of both countries in a way consistent with the zero-lower bound constraint. In here, however, I proceed under the relaxed assumption that the zero-lower bound constraint - at least as an approximation - is binding only for the Home country and, therefore, I consider only the mapping between expectations and survey data for the Home real interest rate given by the vector $\left(\mathbb{E}_{t}\left(\widehat{r}_{t+1}\right), \ldots, \mathbb{E}_{t}\left(\widehat{r}_{t+h}\right)\right)$.

Given the Fisher equation in (74), it follows that the Home real interest rate and its expectations at different horizons $h \geq 0$ can be constructed as:

$$
\begin{aligned}
& \text { if } h=0, \widehat{r}_{t} \approx \widehat{i}_{t}-\mathbb{E}_{t}\left(\widehat{\pi}_{t+1}\right), \forall t, \\
& \text { if } h>0, \mathbb{E}_{t}\left(\widehat{r}_{t+h}\right) \approx \mathbb{E}_{t}\left(\widehat{i}_{t+h}\right)-\mathbb{E}_{t}\left(\widehat{\pi}_{t+h+1}\right), \forall t .
\end{aligned}
$$

The current short-term Home nominal interest rate, $\widehat{i}_{t}$, is observable as it is the survey data on expected Home inflation $h$-quarters ahead, $\mathbb{E}_{t}^{\text {survey }}\left(\widehat{\pi}_{t+h}\right)$, and on the expected Home short-term nominal interest rate $h$-quarters ahead, $\mathbb{E}_{t}^{\text {survey }}\left(\widehat{i}_{t+h}\right)$. In mapping the equations (96) - (97) to the data, I posit these measurement equations which introduce measurement error on the expected future Home real interest rate as follows:

$$
\begin{aligned}
& \text { if } h=0, \widehat{r}_{t} \approx \widehat{i}_{t}-\mathbb{E}_{t}^{\text {survey }}\left(\widehat{\pi}_{t+1}\right), \forall t, \\
& \text { if } h>0, \mathbb{E}_{t}\left(\widehat{r}_{t+h}\right) \approx \mathbb{E}_{t}^{\text {survey }}\left(\widehat{r}_{t+h}\right) \approx \mathbb{E}_{t}^{\text {survey }}\left(\widehat{i}_{t+h}\right)-\mathbb{E}_{t}^{\text {survey }}\left(\widehat{\pi}_{t+h+1}\right)+\widehat{o}_{t}^{h}, \forall t,
\end{aligned}
$$

where the vector of measurement error terms $\left\{\hat{o}_{t}^{h}\right\}$ is modeled in the form of i.i.d., uncorrelated Gaussian white noise:

$$
\widehat{o}_{t}^{h} \sim N\left(0, \sigma_{h}^{2}\right), \forall h>0, \forall t
$$

Hence, (98) - (99) is a straightforward case of the general-form in equation (47). Moreover, it follows in this case that $\left\{\mathbb{E}_{t}\left(\widehat{Y}_{t+1}^{g}\right)\right\}=\left\{\mathbb{E}_{t}\left(\widehat{r}_{t+1}\right), \ldots, \mathbb{E}_{t}\left(\widehat{r}_{t+h}\right)\right\}$ which then must correspond to the observable survey data vector $\left\{\mathbb{E}_{t}^{\text {survey }}\left(\widehat{Y}_{t+1}^{g}\right)\right\}=\left\{\mathbb{E}_{t}^{\text {survey }}\left(\widehat{r}_{t+1}\right), \ldots, \mathbb{E}_{t}^{\text {survey }}\left(\widehat{r}_{t+h}\right)\right\}$. 
With all of this, I can cast the first-order approximation of the main equilibrium conditions of the two-country workhorse New Keynesian model into the general-form given by (44) - (47) using survey-based data to implicitly recognize the impact of the zero-lower bound on the estimated model. In other words, this specification suffices to estimate the key structural parameters of the model and, most importantly, to recover the U.S. natural rate of interest while internalizing the impact of the zero-lower bound in the U.S. on the decisions of private agents and policymakers via survey data on expectations. The vector of observables including expectations is, therefore, $\widehat{\widetilde{Y}}_{t}^{o} \equiv\left(\widehat{\pi}_{t}, \widehat{\pi}_{t}^{*}, \widehat{y}_{t}-\widehat{l}_{t}, \widehat{y}_{t}^{*}-\widehat{l}_{t}^{*}, \widehat{r}_{t}, \hat{i}_{t}^{*}, \mathbb{E}_{t}^{\text {survey }}\left(\widehat{r}_{t+1}\right), \ldots, \mathbb{E}_{t}^{\text {survey }}\left(\widehat{r}_{t+h}\right)\right)^{T}$ or, simply, $\widehat{\widetilde{Y}}_{t}^{o} \equiv\left(\widehat{\pi}_{t}, \widehat{\pi}_{t}^{*}, \widehat{a}_{t}, \widehat{a}_{t}^{*}, \widehat{r}_{t}, \widehat{i}_{t}^{*}, \mathbb{E}_{t}^{\text {survey }}\left(\widehat{r}_{t+1}\right), \ldots, \mathbb{E}_{t}^{\text {survey }}\left(\widehat{r}_{t+h}\right)\right)^{T}$.

\subsubsection{Matching Model Variables to the Data}

I use the log-linear equilibrium conditions of the workhorse open-economy model described in general-form in (44) - (47) as the structural framework for my estimation. I use data for the U.S. and its 33 major trading partners. All data is collected from the Congressional Budget Office (CBO (2020)), the Federal Reserve Bank of Dallas' Database of Global Economic Indicators (Grossman et al. (2014)), and the Conference Board Total Economy Database ${ }^{\mathrm{TM}}$ (Conference Board (2020)), while the survey data is from Blue Chips Economic Indicators (Aspen Publishers (2020)). The time series on this dataset starts in 1984:Q1 with the onset of the Great Moderation period as dated by McConnell and Pérez-Quirós (2000) and ends in 2019:Q4. The full sample period, therefore, covers not just the Great Moderation but also the 2007 - 09 global financial recession and its aftermath, including the period when the U.S. policy rate was constrained at the zero-lower bound. For a number of the series the data can be extended back in time to 1980:Q1 as needed.

The U.S. macro data is all from CBO (2020) and includes: (1) the quarter-over-quarter annualized inflation rate of the Consumer Price Index For All Urban Consumers (CPI-U): All Items $(\mathrm{SA}, 1982-84=1)\left(\Delta \ln C P I_{t}^{U . S}\right) ;(2)$ measured labor productivity calculated as the ratio between Real Gross Domestic Product (SAAR, Mil.Chn.2012.\$) and the civilian employment recovered from the Civilian Labor Force: 16 Years and Over (SA, Mil.) multiplied by one minus the Civilian Unemployment Rate: 16 Years and Over (SA, in units) (ln $L P_{t}^{\text {U.S. }}$ ); and (3) the nominal 3-Month Treasury Bill Yield (\%, per annum) $\left(i_{t}^{U . S .}\right)$. The U.S. survey data is from Aspen Publishers (2020) and it includes: (1) quarterly averages of the monthly reports of the Consumer Price Index Consensus Forecasts one-quarter to five-quarters ahead in quarter-over-quarter (annualized) percent change $\left(\mathbb{E}_{t}^{\text {survey }}\left(\Delta \ln C P I_{t+1}^{U . S .}\right), \ldots, \mathbb{E}_{t}^{\text {survey }}\left(\Delta \ln C P I_{t+5}^{U . S .}\right)\right)$; and (2) quarterly averages of the monthly 
reports of the 3-Month Treasury Bill Yield Consensus Forecasts one-quarter to four-quarters ahead in percent (per annum) $\left(\mathbb{E}_{t}^{\text {survey }}\left(i_{t+1}^{U . S .}\right), \ldots, \mathbb{E}_{t}^{\text {survey }}\left(i_{t+4}^{U . S}\right)\right)$. From Aspen Publishers (2020), I also obtain: (1) the 5-year expected average, 5-years forward of the annual CPI inflation rate $\left(\mathbb{E}_{t}^{\text {survey }}\left(\Delta^{a n n} \ln C P I_{y+5 \rightsquigarrow y+10}^{U . S .}\right)\right.$ where the subscript $y$ refers to the current year and $\Delta^{a n n}$ refers to the annual growth rate); and (2) the 5-year expected average, 5-years forward of the annual 3-Month Treasury Bill Yield $\left(\mathbb{E}_{t}^{\text {survey }}\left(i_{y+5 \rightsquigarrow y+10}^{a n n, U . S .}\right)\right.$ where the superscript ann refers to annual data). I interpret these long-range forecasts, $\mathbb{E}_{t}^{\text {survey }}\left(\Delta^{\text {ann }} \ln C P I_{y+5 \rightsquigarrow y+10}^{U . S .}\right)$ and $\mathbb{E}_{t}^{\text {survey }}\left(i_{y+5 \rightsquigarrow y+10}^{a n n, U . S .}\right)$, as survey-based estimates of the trend component of inflation and the short-term nominal interest rates. ${ }^{12}$

The data that I collect from Grossman et al. (2014) and Conference Board (2020) are the closest analogs for 33 of the largest trading partners of the U.S. and includes: (1) the quarter-over-quarter annualized inflation rate on headline $\mathrm{CPI}\left(\Delta \ln C P I_{t}^{R o W}\right)$; (2) the measured labor productivity $\left(\ln L P_{t}^{R o W}\right)$; and (3) the short-term nominal interest rate in percent per annum $\left(i_{t}^{R o W}\right) .{ }^{13}$ All of the country macro data is from Grossman et al. (2014) except employment for which I rely on the Persons Employed (thousands) annual series from the Conference Board (2020). The Conference Board (2020) employment data is interpolated at quarterly frequency with the Denton-Chollette interpolation method (as in Dagum and Cholette (2006)). With that, I compute the measured labor productivity of each country using the quarterly real GDP series from Grossman et al. (2014) as the numerator and the interpolated employment series as the denominator. The rest-of-the-world aggregates that pull together the data for all 33 foreign countries for each of these three macro variables are constructed using weights reflecting the intensity of bilateral trade between the U.S. and each one of the 33 countries, as explained in Grossman et al. (2014).

Mapping the endogenous variables of the workhorse open-economy New Keynesian model in $\widehat{\widetilde{Y}}_{t}^{o} \equiv\left(\widehat{\pi}_{t}, \widehat{\pi}_{t}^{*}, \widehat{y}_{t}-\widehat{l}_{t}, \widehat{y}_{t}^{*}-\widehat{l}_{t}^{*}, \widehat{r}_{t}, \widehat{i}_{t}^{*}, \mathbb{E}_{t}^{\text {survey }}\left(\widehat{r}_{t+1}\right), \ldots, \mathbb{E}_{t}^{\text {survey }}\left(\widehat{r}_{t+h}\right)\right)^{T}$ to the observed data

\footnotetext{
${ }^{12}$ The long-range survey estimates are 5-year expected average, 5-years forward in the following sense: take the first release of 1984, then the data that I use is the expected average over the period between 1990 and 1994. These long-range estimates are only available regularly on March and October of each year. I match the March report numbers with Q1 and Q2 and the October report numbers with Q3 and Q4.

${ }^{13}$ The countries other than the U.S. included in our sample are: Australia, Austria, Belgium, Bulgaria, Canada, Chile, China, Colombia, Costa Rica, Czech Republic, France, Germany, Greece, Hungary, India, Indonesia, Italy, Japan, Malaysia, Netherlands, Nigeria, Philippines, Poland, Portugal, Russia, South Africa, South Korea, Spain, Sweden, Switzerland, Taiwan, Thailand, and the U.K.
} 
$\widehat{\widetilde{Y}}_{t}^{o b s}$ obtained from the sources collected in

$$
\left(\begin{array}{c}
\Delta \ln C P I_{t}^{U . S .}, \Delta \ln C P I_{t}^{R o W}, \ln L P_{t}^{U . S .}, \ln L P_{t}^{R o W}, i_{t}^{U . S .}, i_{t}^{\text {RoW }} ; \\
\mathbb{E}_{t}^{\text {survey }}\left(\Delta \ln C P I_{t+1}^{U . S .}\right), \ldots, \mathbb{E}_{t}^{\text {survey }}\left(\Delta \ln C P I_{t+5}^{U . S .}\right), \mathbb{E}_{t}^{\text {survey }}\left(i_{t+1}^{\text {U.S. }}\right), \ldots, \mathbb{E}_{t}^{\text {survey }}\left(i_{t+4}^{U . S .}\right) \\
\mathbb{E}_{t}^{\text {survey }}\left(\Delta^{\text {ann }} \ln C P I_{y+5 \rightsquigarrow y+10}^{U . S .}\right), \mathbb{E}_{t}^{\text {survey }}\left(i_{y+5 \rightsquigarrow y+10}^{\text {ann,U.S. }}\right)
\end{array}\right)
$$

requires that I filter the trend out of the observed data before estimation. Most business cycle models like the one I explore in this paper are agnostic about trends and are better suited to investigate fluctuations at business cycle frequencies, so it is customary to rely on filtered data as I do here. For filtering the data, I exploit the available long-range survey-based forecasts given by $\left(\mathbb{E}_{t}^{\text {survey }}\left(\Delta^{\text {ann }} \ln C P I_{y+5 \rightsquigarrow y+10}^{U . S .}\right), \mathbb{E}_{t}^{\text {survey }}\left(i_{y+5 \rightsquigarrow y+10}^{\text {ann,U.S. }}\right)\right)^{T}$ whenever possible as I explain in the remainder of this section.

For this, I postulate the following set of Home country observation equations:

$$
\begin{aligned}
\Delta \ln C P I_{t}^{U . S .} & =\bar{\pi}_{t}^{\text {long-run }}+\widehat{\pi}_{t}, \\
\ln L P_{t}^{U . S .} & =\bar{a}+\widehat{a}_{t}^{T}+\left(\widehat{y}_{t}-\widehat{l}_{t}\right), \\
\widehat{a}_{t}^{T} & =\widehat{a}^{T}+\widehat{a}_{t-1}^{T}+\eta_{t}^{a^{T}}, \eta_{t}^{a^{T}} \sim \text { i.i.d.N }\left(0, \sigma_{a^{T}}^{2}\right), \\
i_{t}^{U . S .}-\mathbb{E}_{t}^{\text {survey }}\left(\Delta \ln C P I_{t+1}^{U . S .}\right) & =r_{t}^{\text {U.S. }}=\bar{i}_{t}^{\text {long-run }}-\bar{\pi}_{t}^{\text {long-run }}+\widehat{r}_{t},
\end{aligned}
$$

the observation equations on the expected path of the Home real interest rate from onequarter-ahead to four-quarters-ahead:

$$
\begin{aligned}
\mathbb{E}_{t}^{\text {survey }}\left(r_{t+h}^{U . S .}\right) & =\mathbb{E}_{t}^{\text {survey }}\left(i_{t+h}^{\text {U.S. }}\right)-\mathbb{E}_{t}^{\text {survey }}\left(i_{t+1+h}^{\text {U.S. }}\right) \\
& =\bar{i}_{t}^{\text {long-run }}-\bar{\pi}_{t}^{\text {long-run }}+\mathbb{E}_{t}^{\text {survey }}\left(\widehat{r}_{t+h}\right), \text { for } h=1, \ldots, 4, \\
\mathbb{E}_{t}^{\text {survey }}\left(\Delta \ln C P I_{t+h}^{\text {U.S. }}\right) & =\bar{\pi}_{t}^{\text {long-run }}+\mathbb{E}_{t}^{\text {survey }}\left(\widehat{\pi}_{t+h}\right), \text { for } h=1, \ldots, 5, \\
\mathbb{E}_{t}^{\text {survey }}\left(i_{t+h}^{\text {U.S. }}\right) & =\bar{i}_{t}^{\text {long-run }}+\mathbb{E}_{t}^{\text {survey }}\left(\widehat{i}_{t+h}\right), \text { for } h=1, \ldots, 4,
\end{aligned}
$$

and, similarly, the following set of Foreign country observation equations:

$$
\begin{aligned}
\Delta \ln C P I_{t}^{R o W}= & \bar{\pi}_{t}^{\text {long-run* }}+\widehat{\pi}_{t}^{*} \\
\ln L P_{t}^{R o W}= & \bar{a}^{*}+\widehat{a}_{t}^{T *}+\left(\widehat{y}_{t}^{*}-\widehat{l}_{t}^{*}\right) \\
& \widehat{a}_{t}^{T *}=\bar{a}^{T *}+\widehat{a}_{t-1}^{T *}+\eta_{t}^{a^{T *}}, \eta_{t}^{a^{T *}} \sim \text { i.i.d.N }\left(0, \sigma_{a^{T *}}^{2}\right), \\
i_{t}^{R o W}= & \bar{i}_{t}^{\text {long-run* }}+\widehat{i}_{t}^{*}
\end{aligned}
$$


where I implicitly assert that the long-run real interest rate is constructed as $\bar{r}_{t}^{\text {long-run }}=$ $\bar{i}_{t}^{\text {long-run }}-\bar{\pi}_{t}^{\text {long-run }}$. The equations in (101) - (109) map the observable series to the endogenous variables in the model distinguishing the permanent component from the cyclical component that is characterized by the model. Given that theory is silent about trends in the data, I adopt a rather flexible approach that relies heavily on survey-based data. The trend components on expected Home inflation and expected Home nominal short-term interest rates are tied to the observable survey-based long-range forecasts as:

$$
\begin{aligned}
\mathbb{E}_{t}^{\text {survey }}\left(\Delta \ln C P I_{y+5 \rightsquigarrow y+10}^{U . S .}\right) & \approx \bar{\pi}_{t}^{\text {long-run }} \approx \bar{\pi}_{t}^{\text {long-run* }} \\
\mathbb{E}_{t}^{\text {survey }}\left(i_{y+5 \rightsquigarrow y+10}^{\text {ann,U.S. }}\right) & \approx \bar{i}_{t}^{\text {long-run }} \approx \bar{i}_{t}^{\text {long-run* }}
\end{aligned}
$$

with trends that are thought to be consistent across countries (more on this point later).

I retain the customary assumption that the deterministic steady state real interest rate is constant and equal to 2 , i.e.,

$$
\bar{r} \equiv-400 \ln (\beta)=2,
$$

but allow for time variation away from the steady state as incorporated in the long-range expectations of private agents. I also maintain the assumption that the long-run trends on inflation and nominal interest rates ought to be the same in both countries. The assumption of approximately equal long-run inflation rates is consistent with the inherent symmetry of the theoretical model and is also in part related to the idea explored elsewhere in the literature that global inflation comovements are largely attributable to a common trend component (see, e.g., Mumtaz and Surico (2012) and Kabukcuoglu and Martínez-García (2018)). The assumption that nominal interest rates are consistent is motivated by the fact that theory requires the real interest rate to converge to its steady state in the long-run which is common across countries. That, together with the consistency of long-run inflation, implies that long-run nominal interest rates ought to be consistent or near consistent as well. The practical advantage of these assumptions is that I can appeal to those in order to proxy the unobserved rest-of-the-world long-range inflation and nominal interest rate trends with the (observed) survey-based long-range forecasts of U.S. inflation and of the U.S. nominal short-term interest rate as implied by $(110)-(111)$.

Finally, since the labor productivity series are not in levels but constructed as an index, I adopt the standard normalization of setting $\bar{a}=\bar{a}^{*}=0$ in equations (102) and (108). I identify the permanent component on labor productivity with a random walk with drift. Then, I remove the trends in the U.S. and rest-of-the-world labor productivity series relying 
on the Beveridge-Nelson decomposition to extract the cycle from the observed data. The detrended series are what I ultimately use to estimate the structural model to be consistent with the cyclical nature of the theory.

Detrending Inflation and Real Interest Rates. Detrending inflation in equations (101) and (107) is rather straightforward given that I identify the observable counterparts of $\bar{\pi}_{t}^{\text {trend }}$ and $\bar{\pi}_{t}^{\mathrm{trend} *}$ in (110). In that sense, I use the quarter-over-quarter growth rate for U.S. headline CPI in deviations from the U.S. long-range 5-year average, 5-year forward forecast, that is, I take $\Delta^{a n n} \ln C P I_{t}^{U . S .}-\mathbb{E}_{t}^{\text {survey }}\left(\Delta \ln C P I_{y+5 \rightsquigarrow y+10}^{U . S .}\right)$ as my counterpart for the cyclical Home inflation, $\widehat{\pi}_{t}$. For the rest-of-the-world aggregate, I simply use the quarter-over-quarter growth rate for headline CPI in deviations from the U.S. long-range 5-year average, 5-year forward forecast implying that $\Delta \ln C P I_{t}^{R o W}-\mathbb{E}_{t}^{\text {survey }}\left(\Delta \ln C P I_{y+5 \rightsquigarrow y+10}^{U . S .}\right)$ is my empirical counterpart for the cyclical Foreign inflation, $\widehat{\pi}_{t}^{*}$.

Analogously, I can remove the trend on expected U.S. inflation in equation (105) with the U.S. long-range inflation forecast in (110) such that $\mathbb{E}_{t}^{\text {survey }}\left(\Delta \ln C P I_{t+h}^{U . S .}\right)-\mathbb{E}_{t}^{\text {survey }}\left(\Delta \ln C P I_{y+5 \rightsquigarrow y+10}^{U . S .}\right)$ is the empirical counterpart of $\mathbb{E}_{t}\left(\widehat{\pi}_{t+h}\right)$. Moreover, I can remove the trend on expected U.S. short-term nominal interest rate in (106) with (111) such that $\mathbb{E}_{t}^{\text {survey }}\left(i_{t+h}^{\text {U.S. }}\right)-\mathbb{E}_{t}^{\text {survey }}\left(i_{y+5 \rightsquigarrow y+10}^{\text {ann,U.S. }}\right)$ is the empirical counterpart of $\mathbb{E}_{t}\left(\widehat{i}_{t+h}\right)$. In here, I need to make a small clarification. Ideally, equations (105) and (106) should be described more generally in the following terms:

$$
\begin{aligned}
\mathbb{E}_{t}^{\text {survey }}\left(\Delta \ln C P I_{t+h}^{U . S .}\right) & =\mathbb{E}_{t}\left(\bar{\pi}_{t+h}^{\text {long-run }}\right)+\mathbb{E}_{t}^{\text {survey }}\left(\widehat{\pi}_{t+h}\right), \\
\mathbb{E}_{t}^{\text {survey }}\left(i_{t+h}^{\text {U.S. }}\right) & =\mathbb{E}_{t}\left(\bar{i}_{t+h}^{\text {long-run }}\right)+\mathbb{E}_{t}^{\text {survey }}\left(\widehat{i}_{t+h}\right)
\end{aligned}
$$

where the long-run inflation and the long-run nominal interest rate are defined as $\bar{\pi}_{t+h}^{\text {long-run }} \equiv$ $\mathbb{E}_{t+h}\left(\bar{\pi}_{i \rightsquigarrow+\infty}\right)$ and $\bar{i}_{t+h}^{\text {long-run }} \equiv \mathbb{E}_{t+h}\left(\bar{i}_{i \rightsquigarrow+\infty}\right)$ for all $h>0$. Giving the properties of the expectations operator, it follows from those definitions that $\mathbb{E}_{t}\left(\bar{\pi}_{t+h}^{\text {long-run }}\right)=\mathbb{E}_{t}\left(\mathbb{E}_{t+h}\left(\bar{\pi}_{i \rightsquigarrow+\infty}\right)\right)=$ $\mathbb{E}_{t}\left(\bar{\pi}_{i \rightsquigarrow+\infty}\right)=\bar{\pi}_{t}^{\text {long-run }}$ which is implicit in (105). Similar reasoning implies that $\mathbb{E}_{t}\left(\bar{i}_{t+h}^{\text {long-run }}\right)=$ $\mathbb{E}_{t}\left(\mathbb{E}_{t+h}\left(\bar{i}_{i \rightsquigarrow+\infty}\right)\right)=\mathbb{E}_{t}\left(\bar{i}_{i \rightsquigarrow+\infty}\right)=\bar{i}_{t}^{\text {long-run }}$ as expected under the terms of (106). This is the rationale to use equation (110) to remove the trend from U.S. inflation expectations as well as from U.S. realized inflation and why I use (111) to detrend the U.S. short-term nominal interest rate and U.S. short-term nominal rate expectations.

It easily follows from (103) and (104) that the detrended U.S. real interest rate and its 
expected path up to 4 quarters ahead can be approximated as:

$$
\begin{aligned}
r_{t}^{U . S .} & =i_{t}^{U . S .}-\mathbb{E}_{t}^{\text {survey }}\left(\Delta \ln C P I_{t+1}^{U . S .}\right) \\
& =\mathbb{E}_{t}^{\text {survey }}\left(i_{y+5 \rightsquigarrow y+10}^{\text {ann }, \text { U.S. }}\right)-\mathbb{E}_{t}^{\text {survey }}\left(\Delta \ln C P I_{y+5 \rightsquigarrow y+10}^{U . S .}\right)+\widehat{r}_{t} \\
\mathbb{E}_{t}^{\text {survey }}\left(r_{t+h}^{\text {U.S. }}\right) & =\mathbb{E}_{t}^{\text {survey }}\left(i_{y+5 \rightsquigarrow y+10}^{\text {ann }, \text { U.S. }}\right)-\mathbb{E}_{t}^{\text {survey }}\left(\Delta \ln C P I_{y+5 \rightsquigarrow y+10}^{U . S .}\right)+\mathbb{E}_{t}^{\text {survey }}\left(\widehat{r}_{t+h}\right), \\
\text { for } h & =1, \ldots, 4 .
\end{aligned}
$$

These variables describe implicitly the course of real interest rates influenced by policymakers. In regards to the rest-of-the-world aggregate, only nominal short-term interest rates are observable. Hence, I use the rest-of-the-world short-term interest rate in deviations from the U.S. long-range 5-year average, 5-year forward forecast of the interest rate implying that $i_{t}^{\text {RoW }}-\mathbb{E}_{t}^{\text {survey }}\left(i_{y+5 \rightsquigarrow y+10}^{\text {ann,U.S. }}\right)$ is my empirical counterpart for the cyclical Foreign nominal interest rate, $\widehat{i}_{t}^{*}$.

All these series as well as the labor productivity series that I discuss next are plotted in Figure A2. All data is reported at quarterly frequency, expressed in percentage terms, and annualized.

Detrending Labor Productivity. The observable labor productivity series are assumed to have an unobserved trend in the form of a random walk with drift. Following on the footsteps of Beveridge and Nelson (1981), Morley et al. (2003), and Morley (2011), I apply the Beveridge-Nelson decomposition (the long-horizon conditional forecast) to detrend the labor productivity data. For a given integrated time series $z_{t}$, the Beveridge-Nelson cycle, $z_{t}^{C}$, is simply the difference between the series itself and its Beveridge-Nelson trend, $z_{t}^{T}$. The Beveridge-Nelson decomposition is often represented in state-space form as:

$$
z_{t}=z_{t}^{T}+z_{t}^{C}
$$

where the permanent component, $z_{t}^{T}$, and the transitory component, $z_{t}^{C}$, are described as:

$$
\begin{aligned}
z_{t}^{T}= & z^{T}+z_{t-1}^{T}+\eta_{t}^{z^{T}}, \eta_{t}^{z^{T}} \sim i . i . d . N\left(0, \sigma_{z^{T}}^{2}\right) \\
\phi(L) z_{t}^{C}= & \theta(L) \varepsilon_{t}^{z^{C}}, \varepsilon_{t}^{z^{C}} \sim i . i . d . N\left(0, \sigma_{z^{C}}^{2}\right) \\
& \operatorname{Corr}\left(\eta_{t}^{z^{T}}, \varepsilon_{t}^{z^{C}}\right)=\rho_{\eta^{z^{T}} \varepsilon^{z^{C}}}
\end{aligned}
$$




\section{Figure A2. U.S. and Rest-of-the-World Dataset for the Estimation}

(In Deviations from Trend)

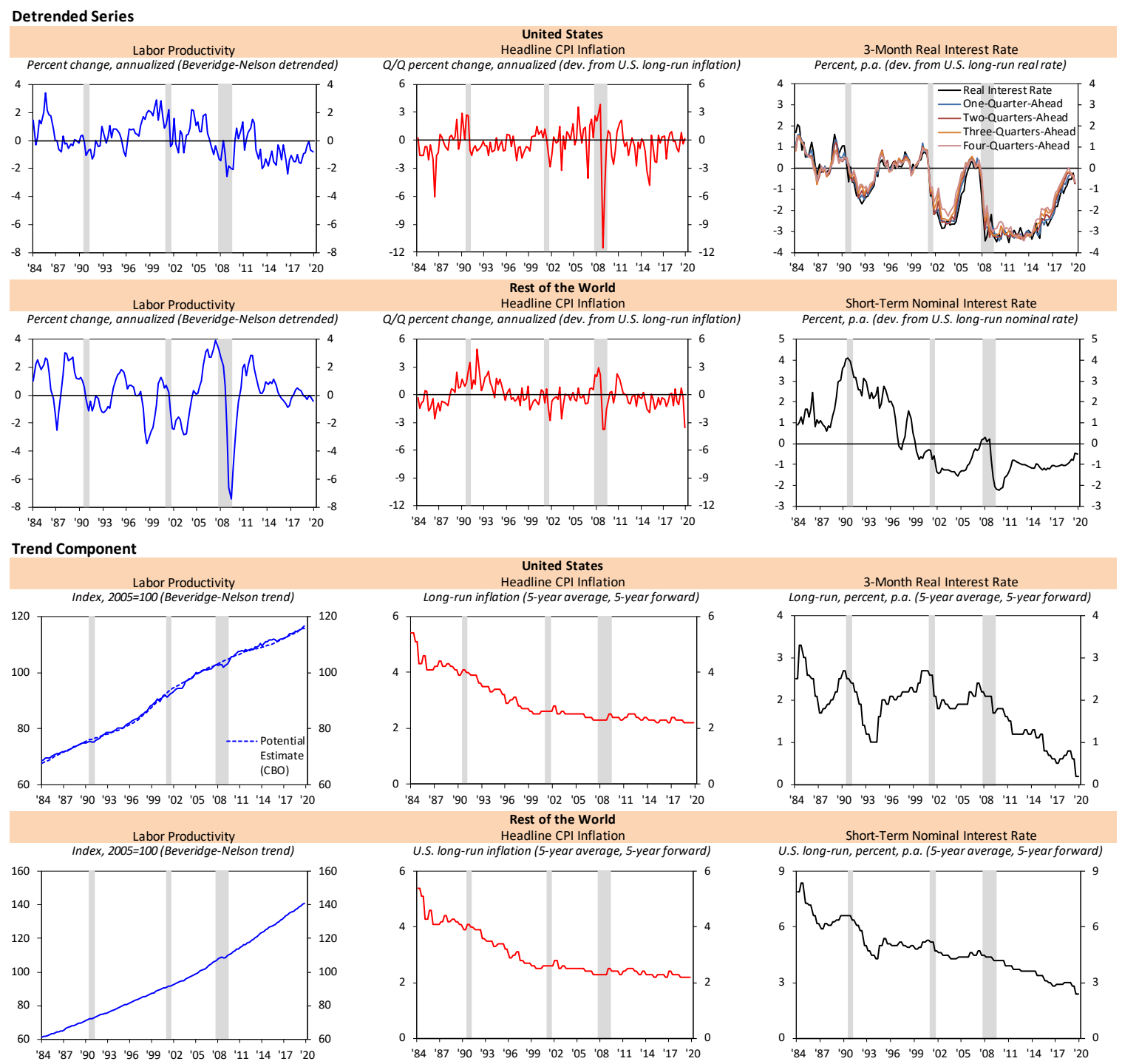

Note: Shaded bars indicate NBER recessions in the U.S. All detrended data is expressed in percent, annualized. The long-run data used to detrend U.S. and rest of the world inflation is the 5-year average, 5-year forward of U.S. CPI inflation from Blue Chips Economic Indicators. The long-run data used to detrend U.S. and rest of the world short-term interest rates is the 5 -year average, 5 -year forward forecast of the U.S. 3-month Treasury bill also from. The labor productivity variables are detrended using a Beveridge-Nelson decomposition with an $\mathrm{AR}(15)$ on the cyclical component and $\mathrm{s}=100$ forecast periods ahead. For the U.S., the trend is the inferred labor productivity trend is compared with the potential output series from the Congressional Budget Office.

Sources: Aspen Publishers (2020); CBO (2020); Conference Board (2020); Grossman et al. (2014); NBER; and author's calculations. 
The observation equations in (102), (103), (108), and (109), can be cast in the general-form of the state-space representation in equations (117) - (120) with a permanent component that takes the form of a random walk with drift and a transitory component that follows some stationary ARMA process with an unconditional mean of zero.

To be more precise, the cyclical part of the observation equations (102) and (108) is related to measured labor productivity, $\left(\widehat{y}_{t}-\widehat{l}_{t}\right)$ and $\left(\widehat{y}_{t}^{*}-\widehat{l}_{t}^{*}\right)$ respectively. Using the linear-in-labor production in (72) - (73), I relate the endogenous labor productivity to the exogenous Home and Foreign productivity shocks, $\widehat{a}_{t}$ and $\widehat{a}_{t}^{*}$. Hence, the specification of the observation equations (that is, the specifications of (102) and (108)) implies that the trend component on the Home and Foreign productivity shocks, $\widehat{a}_{t}^{T}$ and $\widehat{a}_{t}^{T *}$, is directly inherited by the observed labor productivity series, that is, by $\left(\widehat{y}_{t}-\widehat{l}_{t}\right)$ and $\left(\widehat{y}_{t}^{*}-\widehat{l}_{t}^{*}\right)$.

To remove this trend, I convert the observed data on labor productivity into 400 times the natural logarithms for the sample period of 1980:Q1-2019:Q4. Given this, I test for the presence of stochastic trends in the transformed data series using the augmented DickeyFuller unit root test with lag selection based on the Schwarz information criterion (BIC) and I fail to reject the unit root hypothesis against the alternative of stationarity at all conventional significance levels for U.S. labor productivity $(t$-statistic $=-1.017411$ for no lags of difference terms, with a p-value of 0.7465) as well as for the rest-of-the-world labor productivity aggregate $(t$-statistic $=-0.145750$ for one lag of difference terms, with a p-value of 0.9413$)$.

The dynamics of the transitory component, $z_{t}^{C}$, are determined by the log-linearized equilibrium conditions of the structural model. However, here I choose to remain agnostic on the specification of the ARMA structure that underpins the Beveridge-Nelson decomposition keeping it general enough that it provides a reasonably close approximation for the cyclical dynamics of the measured labor productivity (that is, the cyclical dynamics of the productivity shocks). To be precise, partly motivated by the evidence in Morley (2011) and partly by my own exploration of the data, I use an $\mathrm{AR}(15)$ specification as this appears to work well with the measured labor productivity series.

Finally, I apply the Beveridge-Nelson decomposition to the data and extract the cyclical component plotted in Figure A2. ${ }^{14}$ It is worth noting that these estimates imply that measured labor productivity in the U.S. has been significantly below trend since the mid-2000s, even before the 2007 - 09 global financial recession hit the world economy, at a time when most estimates of the U.S. natural rate of interest appear to have taken a dive.

\footnotetext{
${ }^{14}$ The implementation of the Beveridge-Nelson decomposition uses the E-views add-in BNDecom with $s=100$ steps ahead prediction with E-views 10 .
} 


\section{Structural Estimation Approach}

The model contains 22 structural parameters (8 structural parameters, 10 parameters for the exogenous shock processes, and 4 measurement error parameters) to be estimated or calibrated. Here I provide a succinct description of the sources used to parameterize those structural parameters.

\subsection{Parameterization}

Parameters related to the steady state (long-run). Typically, long-run historical averages of the relevant macroeconomic time-series are used to calibrate parameters that affect the steady state of the model. Given my model specification, there are 11 parameters that enter into the deterministic steady state: the intertemporal discount factor, $\beta$, the inverse of the intertemporal elasticity of substitution, $\gamma$, the inverse of the Frisch elasticity of labor supply, $\varphi$, the labor disutility scaling factor, $\kappa$, the share of locally-produced goods, $\xi$, the unconditional mean of the productivity shocks, $A$ and $A^{*}$, the unconditional mean of the "cost-push" shocks, $U$ and $U^{*}$, and the unconditional mean of the monetary policy shocks, $M$ and $M^{*}$.

The parameters $A, A^{*}, U, U^{*}, M, M^{*}$, and $\kappa$ do not affect the dynamics of the model or the dynamics of its flexible price (frictionless) counterpart. Therefore, without loss of generality, given that the optimal labor subsidy implies that $U(1-\phi)=U^{*}\left(1-\phi^{*}\right)=1$, I simply normalize $A=A^{*}=M=M^{*}=\kappa=1$ and obtain a steady state in which output and employment (in levels) for the Home and Foreign countries are all equal to one. Given this normalization, the preference parameters $\gamma$ and $\varphi$ cannot be pinned down by steady state relationships, but the intertemporal discount factor, $\beta$, and the share of imported goods in the consumption basket, $\xi$, can still be matched to historical macroeconomic time series based on steady state relationships. I set the intertemporal discount factor $\beta$ at 0.995012479 to attain a real rate of interest of $2 \%$ annualized (i.e., I choose $\beta$ to imply that $-400 \ln (\beta)=2$ ). However, unlike $\beta$ which is simply calibrated, I allow $\xi$ to be estimated with the rest of the parameters of the model. I set the share of imported goods in the consumption basket which is equal to the parameter $\xi$ at 0.18 to obtain an average import share of $18 \%$ for the U.S. consistent with the evidence reported in Martínez-García (2018).

Parameters related to the model dynamics (short-run). Given my model specification, there are 4 more structural (non-policy) parameters and 2 policy parameters that affect the short-run dynamics of the model. The structural (non-policy) parameters include the 
inverse of the intertemporal elasticity of substitution, $\gamma$, the inverse of the Frisch elasticity of labor supply, $\varphi$, the elasticity of substitution between Home and Foreign bundles, $\sigma$, and the Calvo (1983) price stickiness parameter, $\alpha$. The policy parameters include the sensitivity of the monetary policy rule to inflation deviations from target, $\psi_{\pi}$, and from output deviations from potential, $\psi_{x}$.

Frisch elasticity of labor supply: The Frisch elasticity of labor supply, $\frac{1}{\varphi}$, is commonly identified in the literature on the basis of micro-level data. Pencavel (1986) reports that the typical point estimate of the labor supply elasticity for men is 0.2 , with a range of estimates going from 0 to 0.45. Other surveys on the empirical micro literature include Card (1994), Browning et al. (1999), and Keane (2011). Most micro studies indicate that the Frisch elasticity of labor supply lies below 1. Macro-estimates, in turn, tend to be above 1. For example, Rotemberg and Woodford (1998a) and Rotemberg and Woodford (1998b) argue that the inverse of the Frisch elasticity $\varphi$ needs to be as low as $\frac{1}{9.5}=0.10526$ to match the relatively weak observed response of real wages to monetary disturbances and other macro features of the labor market. Based on the micro evidence, I set the Frisch elasticity of labor supply $\frac{1}{\varphi}$ at 0.2 (i.e., $\varphi$ is set equal to 5) to match Pencavel (1986).

Elasticity of intertemporal substitution: The elasticity of intertemporal substitution, $\frac{1}{\gamma}$, is often identified on the basis of macro-level data. Still, the empirical macro literature provides a wide range of possible values for this parameter. Hall (1988) and Yogo (2004), estimating the inverse of the elasticity of intertemporal substitution $\gamma$ from the comovement of aggregate consumption with the real yields, and argue that its value is likely above 5 . Most business cycle models typically assume a lower value, though (see, e.g., Lucas (1990)). However, I set $\gamma$ equal to 5 in order to be consistent with the international macro literature (e.g., Chari et al. (2002), Martínez-García et al. (2012), and Martínez-García and Wynne (2014) suggest that such a parameterization is important to reasonably approximate the observed volatility in the real exchange rate).

Elasticity of intratemporal substitution between Home and Foreign goods: The elasticity of intratemporal substitution between Home and Foreign goods (or trade elasticity), $\sigma$, is commonly identified on the basis of macro-level data. Based on empirical estimates of trade models, it is generally noted that plausible values of the U.S. elasticity of intratemporal substitution lie between 1 and 2. I follow Backus et al. (1994) and Chari et al. (2002) setting the elasticity $\sigma$ to be equal to 1.5 .

Frequency of price adjustments: The Calvo (1983) parameter, $\alpha$, is often identified using micro-level data. However, the empirical micro literature provides a wide range of possible values for $\alpha$. Bils and Klenow (2004) suggests that the median frequency of price changes 
implies a duration of only 4.3 months based on evidence from the U.S. CPI. Klenow and Kryvtsov (2008) and Nakamura and Steinsson (2008) report a range of 7 - 10 months based on U.S. CPI data, while prices in the Euro-Area CPI appear to change even less frequently according to Dhyne et al. (2006). The evidence surveyed by Taylor (1999) and the micro price studies reviewed by Klenow and Malin (2010) are consistent with the view that prices change on average closer to once a year (after excluding most short-lived price changes). The convention prevalent in most of the literature, which I adopt as well, is that prices remain unchanged for an average of four quarters implying that $\alpha=0.75$ (see, e.g., Chari et al. (2002), Martínez-García et al. (2012), Martínez-García and Søndergaard (2013), and Martínez-García and Wynne (2014), among others).

Policy parameters: I adopt the policy parameter values proposed in Taylor (1993)'s original specification for the U.S. which have worked quite well to describe U.S. monetary policy. Hence, I set $\psi_{\pi}$ at 1.5 and $\psi_{x}$ at 0.5 .

Parameters related to the exogenous shock processes. In the model, there are just three country-specific shocks that I have to consider: productivity shocks, "cost-push" shocks, and monetary policy shocks. Note that equations $(72)-(73)$ tie the cyclical labor productivity series directly to the productivity shocks of the model, $\widehat{a}_{t}$ and $\widehat{a}_{t}^{*}$. Hence, I estimate the restricted specification of the $\operatorname{VAR}(1)$ process for productivity shocks in Table 2 using the cyclical component of the labor productivity series described in the previous section and I obtain the estimates reported in Table 3 below.

The estimates in Table 3 are fairly similar to those found in the literature, albeit somewhat less persistent (e.g., Heathcote and Perri (2002)). Based on the evidence, I set $\delta_{a}$ (the persistence parameter) to $0.865461, \delta_{a, a^{*}}$ (the cross-country spillover parameter) to -0.007733 (although statistically this parameter is no different than zero), and $\rho_{a, a^{*}}$ (the correlation between Home and Foreign innovations) to 0.151807 . The volatility for both series $\sigma_{a}$ is set to a common value of 0.787714 which equals the square root of the variance of the U.S. labor productivity residuals.

The calibration of the monetary policy shock is a bit less straightforward than that of the productivity shock, so I use parameter values for the monetary shock process similar to those estimated by Rudebusch (2002) on an extrinsic Taylor (1993)-type policy rule. For the $\operatorname{VAR}(1)$ monetary policy shock process, I set $\delta_{m}$ at 0.90 for the persistence and $\sigma_{m}$ at 0.50 for the volatility of the process in both countries. I complete the description of the dynamics by choosing the correlation between Home and Foreign monetary innovations $\rho_{m, m^{*}}$ to be set at 0 . I posit the parameters of the "cost-push" shock process to be: $\delta_{u}$ 
(the persistence parameter) equal to $0.50, \sigma_{u}$ (the volatility parameter) equal to 0.10 , and $\rho_{u, u^{*}}$ (the correlation between Home and Foreign "cost-push" shock innovations) equal to 0. Finally, I assume that measurement error volatility is low and, accordingly, set $\sigma_{1}^{2}, \ldots, \sigma_{4}^{2}$ to be 0.15 .

\begin{tabular}{|c|c|c|}
\hline \multicolumn{3}{|c|}{ Table 3 - Summary of Vector Autoregression Estimate } \\
\hline & $\widehat{a}_{t}$ & $\widehat{a}_{t}^{*}$ \\
\hline \multirow{4}{*}{$\widehat{a}_{t-1}$} & 0.865461 & -0.007733 \\
\hline & $(0.02944)$ & $(0.02910)$ \\
\hline & {$[29.3958]$} & {$[-0.26573]$} \\
\hline & -0.007733 & 0.865461 \\
\hline \multirow{2}{*}{$\widehat{a}_{t-1}^{*}$} & $(0.02910)$ & $(0.02944)$ \\
\hline & {$[-0.26573]$} & [29.3958] \\
\hline R-squared & 0.585135 & 0.818548 \\
\hline Sum sq. resids & 87.48970 & 92.43155 \\
\hline Mean dependent & 0.098375 & 0.220576 \\
\hline S.D. dependent & 1.218655 & 1.894021 \\
\hline Determinant resid. covariance & \multicolumn{2}{|c|}{0.397387} \\
\hline Log likelihood & \multicolumn{2}{|c|}{-337.8189} \\
\hline Akaike information criterion & \multicolumn{2}{|c|}{4.752711} \\
\hline Scharwz criterion & \multicolumn{2}{|c|}{4.794150} \\
\hline \multicolumn{3}{|l|}{ Correlation matrix of residuals } \\
\hline & $\widehat{\varepsilon}_{t}^{a}$ & $\widehat{\varepsilon}_{t}^{a *}$ \\
\hline$\widehat{\varepsilon}_{t}^{a}$ & 1 & 0.151807 \\
\hline$\widehat{\varepsilon}_{t}^{a *}$ & 0.151807 & 1 \\
\hline \multicolumn{3}{|l|}{ Covariance matrix of residuals } \\
\hline & $\widehat{\varepsilon}_{t}^{a}$ & $\widehat{\varepsilon}_{t}^{a *}$ \\
\hline$\widehat{\varepsilon}_{t}^{a}$ & 0.620494 & 0.096819 \\
\hline$\widehat{\varepsilon}_{t}^{a *}$ & 0.096819 & 0.655543 \\
\hline
\end{tabular}

Standard errors in () and t-statistics in []. 


\subsection{Eliciting Priors}

My priors on the relevant structural parameters are summarized in Table 4. I maintain these prior distributions invariant in all my subsequent estimations, taking them as given. I only consider prior densities of the Beta, Gamma, Inverse Gamma, Normal, and Uniform distributions as well as the degenerate distribution that puts mass one on a single value. I impose on all cases that the prior mean must be equal to the parameterization of the model discussed in the previous subsection to be consistent with my own reading of the literature and the data. I choose each prior distribution as well as the corresponding dispersion to reflect the degree of ex ante uncertainty that I perceive in the literature regarding those parameter values.

Structural Parameters. As is customary, I use a degenerate prior for the intertemporal discount factor $\beta$ and fix it at 0.995012479 . The frequency of price adjustments is tied to the Calvo (1983) parameter, $\alpha$, and for this I adopt a beta prior centered at 0.75 with a tight prior standard deviation of 0.02 . The values of $\alpha$ and $\beta$ have the implication of constraining

the composite coefficient $\Phi \equiv\left(\frac{(1-\alpha)(1-\beta \alpha)}{\alpha}\right)$ which underpins the slope of the Phillips curve in the model. For the share of imported goods in the consumption basket, $\xi$, I choose a tight Beta distribution as the prior centered around 0.18 with a small standard deviation of 0.01 . This specification emphasizes that with the historically low import share observed for the U.S., one should not expect ex ante the parameter $\xi$ in the model (which defines the degree of trade openness) to be too large.

I adopt the Gamma distribution centered around 5 for the inverse of the intertemporal elasticity of substitution, $\gamma$, and the inverse of the Frisch elasticity of labor supply, $\varphi$. I impose also a loose prior standard deviation of 0.25 on both distributions in order to allow the data more flexibility to shape the posterior. I also adopt the Gamma distribution centered around 1.5 for the intratemporal elasticity of substitution between Home and Foreign bundles, $\sigma$, with a somewhat wide standard deviation of 0.15 in order to recognize the importance of this parameter for the international transmission of shocks while also capturing the uncertainty surrounding its true value.

The parameter for the policy response to deviations from the inflation target, $\psi_{\pi}$, is linearly transformed in order to be consistent with the domain of the Gamma distribution and to rule out violations of the Taylor principle (requiring interest rates to respond more than one-for-one to inflation) which ensures determinacy of the model solution in most of the parameter space. Hence, I estimate $\psi_{\pi}-1$ with a prior centered at 0.5 (which implies a 
prior mean of 1.5 for $\psi_{\pi}$ ) and a prior standard deviation of 0.01. Similarly, I select a Gamma distribution for the parameter that defines the policy response to fluctuations of the output gap, $\psi_{x}$, with a prior mean of 0.5 and a standard deviation of 0.01 .

Parameters of the Shock Processes. I select a Beta prior for the persistence of the productivity shock $\delta_{a}$ as well as for the cross-country spillovers parameter $\delta_{a, a^{*}}$. These two parameters are centered around 0.865461 and -0.007733 , respectively. I also impose pretty tight priors with standard deviations of 0.001 in both cases in order to ensure that the VAR(1) process that describes the productivity shocks remains close to the estimates in Table 3. I select a Beta distribution for the first-order autocorrelation of the monetary shocks, $\delta_{m}$, as well as for the persistence of the "cost-push" shock, $\delta_{u}$. The priors are centered around 0.90 and 0.50 , respectively, with a fairly tight prior standard deviation equal to 0.01.

The prior volatilities of the productivity shock, the monetary shock, and the "cost-push" shock, $\sigma_{a}, \sigma_{m}$, and $\sigma_{u}$, are centered at their parameterized values of $0.787714415,0.50$, and 0.10, respectively. I select an Inverse Gamma distribution to represent the prior of each of these volatility parameters, with a tight standard deviation of 0.001 for the productivity shock volatility and of 0.01 for the others. I choose Beta priors for the cross-country correlation of innovations for each of the shocks, $\rho_{a, a^{*}}, \rho_{m, m^{*}}$, and $\rho_{u, u^{*}}$. I center $\rho_{a, a^{*}}$ at the calibrated value of 0.151807 with a standard deviation of $0.01, \rho_{m, m^{*}}$ at the calibrated value of 0 with a standard deviation of 0.01 , and $\rho_{u, u^{*}}$ at the calibrated value of 0 with a standard deviation of 0.01. Finally, I adopt an Inverse Gamma prior distribution for the measurement error volatilities, $\sigma_{1}, \ldots, \sigma_{4}$, all of which are centered at their parameterized value of 0.15 with a very tight standard deviation of 0.005 . 


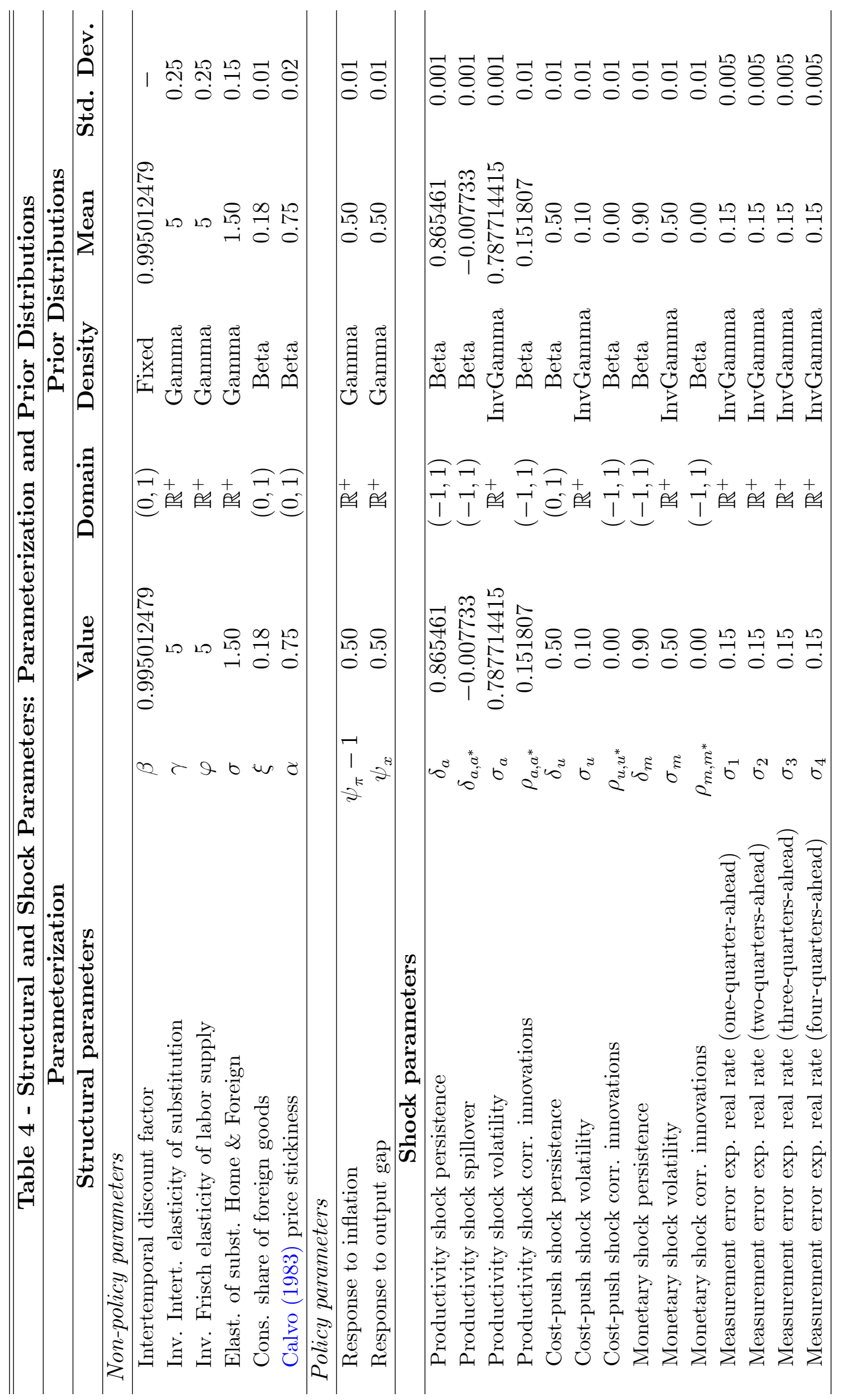

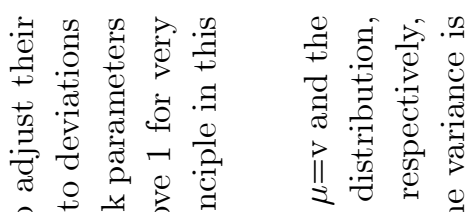

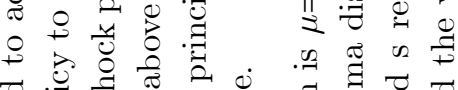

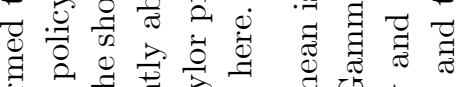

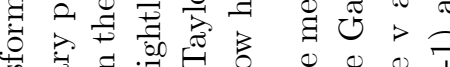

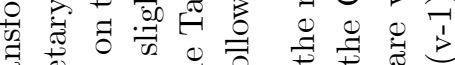

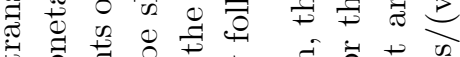

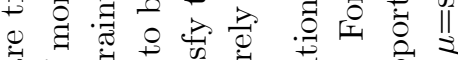

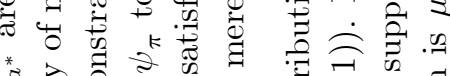

*

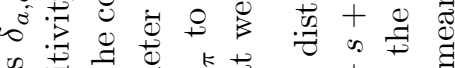

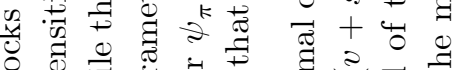

की

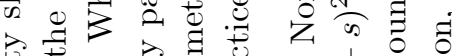

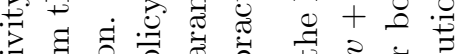

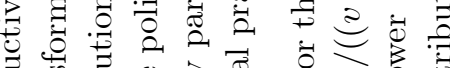

t)

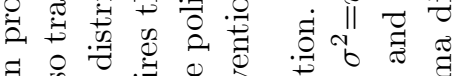

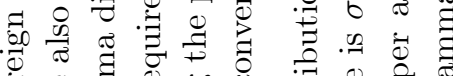

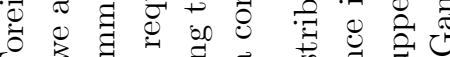

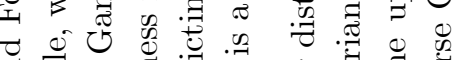

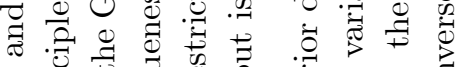

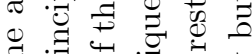

至

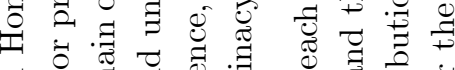

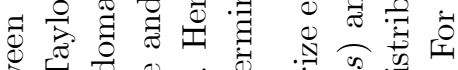

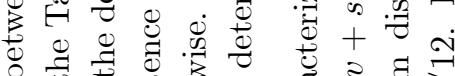

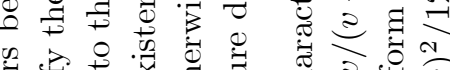

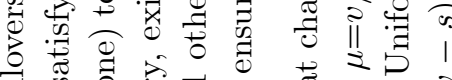

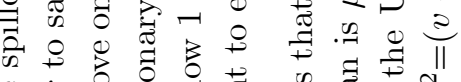

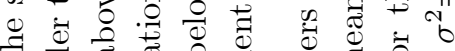

过

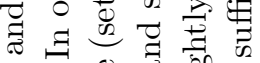

政

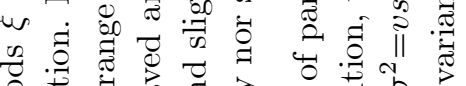

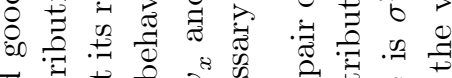

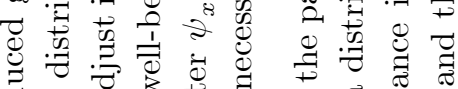

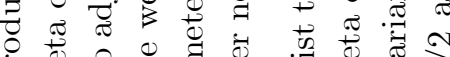

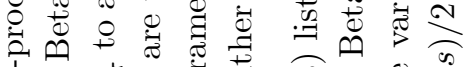

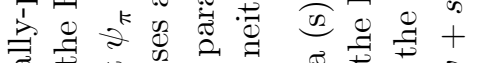

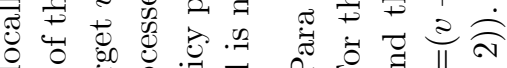

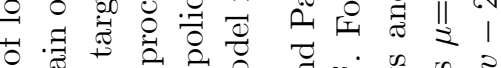

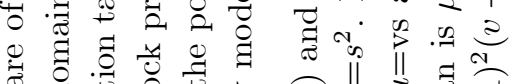

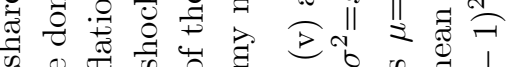

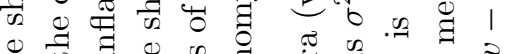

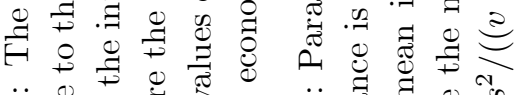

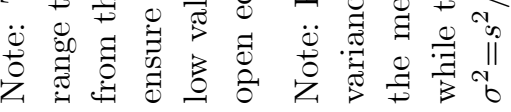




\subsection{Technical Details}

The model solution and the driving processes of the model described previously constitute a linear system of equations that fits naturally into a state-space representation. I estimate such a system of equations with Bayesian methods, as surveyed for example by MartínezGarcía et al. (2012) and Martínez-García and Wynne (2014). Let me denote the prior density of the model parameters $\lambda$ as $p(\lambda)$, the likelihood function by $\mathcal{L}\left(\lambda \mid \widehat{Y}^{\text {obs }}\right)$, and the posterior distribution as $p\left(\lambda \mid \widehat{Y}^{\text {obs }}\right) \propto \mathcal{L}\left(\lambda \mid \widehat{Y}^{\text {obs }}\right) p(\lambda)$. Bayesian estimation combines prior information about the model's parameters with its likelihood function to form a posterior density, from which to draw using standard Markov Chain Monte Carlo (MCMC) algorithms. I construct the likelihood using the Kalman filter based on the log-linear statespace representation of the (reduced-form) solution of the rational expectations model if a unique solution exists. Otherwise, I set to zero the prior probability for those regions of the parameter space that imply non-existence or indeterminacy of the solution.

A Metropolis-Hastings ( $\mathrm{MH})$ algorithm - one of the algorithms of the Markov Chain Monte Carlo (MCMC) class - is used to generate draws from the posterior distribution of the model parameters $\lambda$. Under general regularity conditions, the posterior distribution of $\lambda$ is asymptotically normal. This Monte Carlo-based algorithm generates Markov chains with a stationary distribution that approximates a Gaussian posterior distribution around the mode with a scaled version of the asymptotic covariance matrix. This allows me to efficiently represent the posterior distribution around the mode. I maximize the posterior density kernel with a Newton-type optimization routine. I implement the algorithm with the software package Dynare, using a routine that initializes the $\mathrm{MH}$ algorithm from a point in the parameter space with a high posterior density value (not necessarily the posterior mode). ${ }^{15}$

In this paper I pursue the standard approach to handle the stochastic singularity in Bayesian econometrics (that arises when the model generates a rank-deficient covariance matrix for the observables) and set the number of observables used for the estimation to be equal to the number of structural and measurement error shocks in the model. This limits the amount of time series data that can be incorporated into the estimation and the information available for identification, but otherwise does not restrict the composition of the vector of observables that I can use in the estimation.

\footnotetext{
${ }^{15}$ I refer the interested reader to An and Schorfheide (2007), Martínez-García et al. (2012), and MartínezGarcía and Wynne (2014) for a review of Bayesian techniques in the context of structural DSGE estimation. For further reference on MCMC algorithms, see also Robert and Casella (1999).
} 


\section{References}

An, S. and F. Schorfheide (2007). Bayesian Analysis of DSGE Models. Econometric Reviews 26(2-4), 113-172. https://doi.org/10.1080/07474930701220071.

Aspen Publishers (2020). Blue Chip Economic Indicators. Aspen Publishers/Haver Analytics. http://www.aspenpublishers.com/blue-chip-publications.htm. Accessed on: August $2,2020$.

Backus, D. K., P. J. Kehoe, and F. E. Kydland (1994). Dynamics of the Trade Balance and the Terms of Trade: The J-Curve? American Economic Review 84(1), 84-103.

Beveridge, S. and C. R. Nelson (1981). A New Approach to Decomposition of Economic Time Series into Permanent and Transitory Components with Particular Attention to Measurement of the 'Business Cycle'. Journal of Monetary Economics 7(2), 151-174.

Bils, M. and P. J. Klenow (2004). Some Evidence on the Importance of Sticky Prices. Journal of Political Economy 112(5), 947-985. https://doi.org/10.1086/422559.

Browning, M., L. P. Hansen, and J. J. Heckman (1999). Micro Data and General Equilibrium Models. In J. B. Taylor and M. Woodford (Eds.), Handbook of Macroeconomics, vol. I, Chapter 8, pp. 543-633. Elsevier Science B.V.

Calvo, G. A. (1983). Staggered Prices in a Utility-Maximizing Framework. Journal of Monetary Economics 12(3), 383-398. https://doi.org/10.1016/0304-3932(83)90060-0.

Card, D. (1994). Intertemporal Labor Supply: An Assessment. In C. Sims (Ed.), Advances in Econometrics, pp. 49-78. Cambridge, U.K.: Cambridge University Press.

CBO (2020). Budget and Economic Data. Congressional Budget Office (CBO). https://www.cbo.gov/data/budget-economic-data. Accessed on: August 20, 2020.

Chari, V. V., P. J. Kehoe, and E. R. McGrattan (2002). Can Sticky Price Models Generate Volatile and Persistent Real Exchange Rates? Review of Economic Studies 69(3), 533563. https://doi.org/10.1111/1467-937X.00216.

Conference Board (2020). The Conference Board Total Economy Database ${ }^{\mathrm{TM}}$ - Output, Labor and Labor Productivity, 1950-2019. Conference Board. https://www.conferenceboard.org/data/economydatabase/total-economy-database-productivity. Accessed on: June 13, 2020.

Dagum, E. B. and P. A. Cholette (2006). Benchmarking, Temporal Distribution, and Reconciliation Methods for Time Series. Lecture Notes in Statistics. Springer-Verlag: New York, NY. https://doi.org/10.1007/0-387-35439-5. 
Dhyne, E., L. J. Álvarez, H. Le Bihan, G. Veronese, D. Dias, J. Hoffmann, N. Jonker, P. Lünnemann, F. Rumler, and J. Vilmunen (2006). Price Changes in the Euro Area and the United States: Some Facts from Individual Consumer Price Data. Journal of Economic Perspectives 20(2), 171-192. https://doi.org/10.1257/jep.20.2.171.

Engel, C. (2009). Currency Misalignments and Optimal Monetary Policy: A Reexamination. NBER Working Paper no. 14829(Cambridge, Mass., National Bureau of Economic Research, April).

Grossman, V., A. Mack, and E. Martínez-García (2014). A New Database of Global Economic Indicators. The Journal of Economic and Social Measurement 39(3), 163197. https://www.doi.org/10.3233/JEM-140391. The database can be accessed at: https://www.dallasfed.org/institute/dgei.

Hall, R. E. (1988). Intertemporal Substitution in Consumption. Journal of Political Economy 96(2), 339-357. https://doi.org/10.1086/261539.

Heathcote, J. and F. Perri (2002). Financial Autarky and International Business Cycles. Journal of Monetary Economics 49(3), 601-627. https://doi.org/10.1016/S03043932(02)00103-4.

Kabukcuoglu, A. and E. Martínez-García (2018). Inflation as a Global Phenomenon-Some Implications for Inflation Modelling and Forecasting. Journal of Economic Dynamics and Control 87(2), 46-73. https://doi.org/10.1016/j.jedc.2017.11.006.

Keane, M. P. (2011). Labor Supply and Taxes: A Survey. Journal of Economic Literature 49(4), 961-1075. https://doi.org/10.1257/jel.49.4.961.

Klenow, P. J. and O. Kryvtsov (2008). State-dependent or Time-dependent Pricing: Does It Matter for Recent U.S. Inflation? Quarterly Journal of Economics 123(3), 863-904. https://doi.org/10.1162/qjec.2008.123.3.863.

Klenow, P. J. and B. A. Malin (2010). Microeconomic Evidence on Price-Setting. In B. M. Friedman and M. Woodford (Eds.), Handbook of Monetary Economics, Volume 3, Chapter 6, pp. 231-284. Elsevier.

Lucas, R. E. J. (1990). Supply-Side Economics: An Analytical Review. Oxford Economic Papers 42(2), 293-316. https://doi.org/10.1093/oxfordjournals.oep.a041948.

Martínez-García, E. (2015). The Global Content of Local Inflation: Revisiting the Empirical Content of the Global Slack Hypothesis. In W. Barnett and F. Jawadi (Eds.), Monetary Policy in the Context of the Financial Crisis: New Challenges and Lessons, 
pp. 51-112. Emerald Group Publishing Limited. https://doi.org/10.1108/s1571038620150000024016.

Martínez-García, E. (2018). Modeling Time-Variation Over the Business Cycle (19602017): An International Perspective. Studies in Nonlinear Dynamics and Econometrics 22(5), 1-25. https://doi.org/10.1515/snde-2017-0101.

Martínez-García, E. (2019). Good Policies or Good Luck? New Insights on Globalization and the International Monetary Policy Transmission Mechanism. Computational Economics 54(1), 419-454. https://doi.org/10.1007/s10614-017-9746-9.

Martínez-García, E. (2020a). A Matter of Perspective: Mapping Linear Rational Expectations Models into Finite-Order VAR Form. Globalization Institute Working Paper 389. May. https://doi.org/10.24149/gwp389.

Martínez-García, E. (2020b). Get the Lowdown: The International Side of the Fall in the U.S. Natural Rate of Interest. Globalization Institute Working Paper no. 403. October. https://doi.org/10.24149/gwp403.

Martínez-García, E. and J. Søndergaard (2013). Investment and Real Exchange Rates in Sticky Price Models. Macroeconomic Dynamics 17(2), 195-234. https://doi.org/10.1017/S1365100511000095.

Martínez-García, E., D. Vilán, and M. A. Wynne (2012). Bayesian Estimation of NOEM Models: Identification and Inference in Small Samples. Advances in Econometrics 28, 137-199. DSGE Models in Macroeconomics: Estimation, Evaluation, and New Developments (Advances in Econometrics, Volume 28). https://doi.org/10.1108/s07319053(2012)0000028007.

Martínez-García, E. and M. A. Wynne (2010). The Global Slack Hypothesis. Federal Reserve Bank of Dallas Staff Papers, 10. September. https://goo.gl/uqSXM1.

Martínez-García, E. and M. A. Wynne (2014). Assessing Bayesian Model Comparison in Small Samples. Advances in Econometrics 34, 71-115. Bayesian Model Comparison (Advances in Econometrics, Volume 34). https://doi.org/10.1108/s0731905320140000034006.

McConnell, M. M. and G. Pérez-Quirós (2000). Output Fluctuations in the United States: What Has Changed Since the Early 1980's? American Economic Review 90(5), 14641476. http://doi.org/10.1257/aer.90.5.1464. 
Morley, J. C. (2011). The Two Interpretations Of The BeveridgeNelson Decomposition. Macroeconomic Dynamics 15(3), 419-439. https://doi.org/10.1017/S1365100510000118.

Morley, J. C., C. R. Nelson, and E. Zivot (2003). Why Are the Beveridge-Nelson and Unobserved-Components Decompositions of GDP So Different? The Review of Economics and Statistics 85(2), 235-243. https://doi.org/10.1162/003465303765299765.

Mumtaz, H. and P. Surico (2012). Evolving International Inflation Dynamics: World and Country-Specific Factors. Journal of the European Economic Association 10(4), 716734. https://doi.org/10.1111/j.1542-4774.2012.01068.x.

Nakamura, E. and J. Steinsson (2008). Five Facts About Prices: A Reevaluation of Menu Cost Models. Quarterly Journal of Economics 123(4), 1415-1464. https://doi.org/10.1162/qjec.2008.123.4.1415.

Pencavel, J. (1986). Labor Supply of Men: A Survey. In O. Ashenfelter and R. Layard (Eds.), Handbook of Labor Economics. Volume I, Chapter 1, pp. 3-102. Elsevier Science Publishers BV.

Robert, C. and G. Casella (1999). Monte Carlo Statistical Methods. New York: Springer Verlag.

Rotemberg, J. J. and M. Woodford (1998a). An Optimization-Based Econometric Model for the Evaluation of Monetary Policy. In B. S. Bernanke and J. J. Rotemberg (Eds.), NBER Macroeconomics Annual 1997, vol. 12, Volume 12, pp. 297-346. Cambridge, Massachusetts, USA: MIT University Press. https://doi.org/10.2307/3585236.

Rotemberg, J. J. and M. Woodford (1998b). Interest Rate Rules in an Estimated Sticky Price Model. In J. B. Taylor (Ed.), Monetary Policy Rules. Chicago, Illinois, USA: University of Chicago Press.

Rudebusch, G. D. (2002). Term Structure Evidence on Interest Rate Smoothing and Monetary Policy Inertia. Journal of Monetary Economics 49(6), 1161-1187. https://doi.org/10.1016/S0304-3932(02)00149-6.

Taylor, J. B. (1993). Discretion versus Policy Rules in Practice. Carnegie-Rochester Conference Series on Public Policy 39, 195-214. https://doi.org/10.1016/01672231(93)90009-1.

Taylor, J. B. (1999). Staggered Price and Wage Setting in Macroeconomics. In J. B. Taylor and M. Woodford (Eds.), Handbook of Macroeconomics, Vol. 1B, Volume 1B, 
Chapter 15, pp. 1009-1050. Amsterdam: Elsevier/North Holland.

Yogo, M. (2004). Estimating the Elasticity of Intertemporal Substitution When Instruments Are Weak. Review of Economics and Statistics 86(3), 797-810. https://doi.org/10.1162/0034653041811770. 